\title{
Chapter 3 \\ Xylem Cavitation and Embolism in Plants \\ Living in Water-Limited Ecosystems
}

\author{
A. Vilagrosa, E. Chirino, J.J. Peguero-Pina, T.S. Barigah, \\ H. Cochard and E. Gil-Pelegrín
}

\begin{abstract}
Water deficit is considered the main limiting factor for the establishment, survival, and growth of plants mainly in water-limited ecosystems. Plants have evolved a wide range of morphologic and functional mechanisms to adapt to arid environments. However, if the tension in the xylem conduits becomes too high, thus xylem cavitation can occur i.e., water column breakage. This results in the hydraulic disconnection of leaves and above-ground parts from roots because xylem conduits are filled with air and water vapor, and this phenomenon is called embolism. Therefore, the resistance of the xylem to cavitation and embolism is of paramount importance for plant functioning. In this chapter, we will review the role of plant hydraulics and xylem cavitation in the context of water-limited ecosystems and their relationship with other plant functional traits and with survival capacity. These topics will be analyzed and discussed on the basis of current knowledge and our research experiences.
\end{abstract}

\footnotetext{
A. Vilagrosa $(\bowtie) \cdot$ E. Chirino

Fundación de la Comunidad Valenciana Centro de Estudios Ambientales del Mediterráneo (CEAM), Unidad Mixta de Investigación Universidad de Alicante-Fundación CEAM,

PO Box 99 E-03080, Alicante, Spain

e-mail: a.vilagrosa@ua.es
}

\section{J.J. Peguero-Pina}

Grup de Recerca en Biologia de les Plantes en Condicions Mediterrànies, Departament de Biologia, Universitat de les Illes Balears, Carretera de Valldemossa, km 7.5 07071, Palma de Mallorca, Balears, Spain

T.S.Barigah $\cdot$ H. Cochard

INRA, UMR 547 PIAF, F-63100, Clermont-Ferrand, France

T.S.Barigah $\cdot$ H. Cochard

Clermont Université, Université Blaise Pascal, UMR 547 PIAF, BP 10448 F-63000,

Clermont-Ferrand, France

E. Gil-Pelegrín

Unidad de Recursos Forestales, Centro de Investigación y Tecnología Agroalimentaria, Avenida de Montañana 930, E-50059, Zaragoza, Spain 


\subsection{Introduction}

A major tradeoff of acquiring $\mathrm{CO}_{2}$ for photosynthesis is the loss of water from plant leaves. Since water is essential for plant correct functioning, its limitation induces many dysfunctions in terrestrial plants. In this sense, soil water availability represents a significant environmental constraint in Mediterranean and other drylands in the world - a fact which may become even more accentuated in the future according to climate change projections (IPCC 2010). Several factors could promote frequent drought events: higher temperatures, earlier snowmelt, higher interannual variability, precipitation regimes with reduced rainfall amounts, and heat waves. Recent studies have linked widespread plant mortality to extreme drought events (Allen et al. 2010 and references herein). However, the effect of drought could be species specific since species from xeric sites can survive low soil water contents while other species from more mesic sites do not (Ryan 2011).

Drought leads to water deficit in plant tissues, which affects many physiological processes and can have mortal consequences for plant growth and survival (Levitt 1980; Larcher 1995). Among these processes, the xylem cavitation and loss of hydraulic conductivity have been recognized to play an important role in plant performance and drought resistance (Tyree and Sperry 1989). Cavitation is defined as the phenomenon of vapor-bubble formation of a flowing liquid in a region where the pressure of the liquid falls below its vapor pressure. This phenomenon occurs in the xylem of vascular plants when the tension of the sap within a conduit becomes high enough that dissolved air within the sap expands to fill vessels or tracheids. As a consequence, vapor-filled (embolized) conduits no longer hold sap, decrease xylem hydraulic conductance which, in its turn leads to stomatal closure, and even to the abscission of leaves, shoot dieback and finally to plant death (Tyree and Sperry 1989; Brodribb and Cochard 2009).

Recognition of the relevance of water transport in plant tissues began several centuries ago, around 1628, with the studies of Harvey and Malpigi (Richter and Cruiziat 2002). Later, Strasburger showed that woody stems immersed in different solutions will readily pull the solution up. In 1892, Joseph Böhm provided experimental proof that water could be lifted to considerable heights and that the force lifting the water had to be a purely physical one (Richter and Cruiziat 2002). Some years later, Dixon and Joly published their ideas and experiments about water transport (Dixon and Joly 1895), and Dixon (1914) wrote the book "Transpiration and the Ascent of Sap in Plants" (Steudle 2001). The cohesion-tension theory put forward in this book to explain the ascent of sap became universally accepted. In the middle of the twentieth century, John Milburn, Melvin Tyree, Martin H. Zimmermann and co-workers renewed and developed experimental approaches to comfort the cohesion-tension theory, hydraulic design, and xylem cavitation (Tyree and Zimmermann 2002; Pickard and Melcher 2005). From these preliminary studies to the present, a significant progress has been made in understanding plant hydraulic architecture including cavitation process and its impact on plant functioning and ecosystem dynamics. Therefore, the number of 
references in which "xylem cavitation" appears has recently shown a sharp increase: in contrast to the nine studies published between 1970 and 1990, there have been 827 publications on this subject from 1990 to 2011 (Source: Web of Science "xylem cavitation"). In addition to studies focused on explaining the functioning of xylem and cavitation processes, several current studies have also highlighted the importance of xylem cavitation and functional plant strategies in the context of climate change and recurrent drought episodes to provide an explanation for relevant mortality events occurring around the world (McDowell et al. 2008; Breshears et al. 2009; Allen et al. 2010).

\subsubsection{Plant Functional Strategies in Water-Limited Ecosystems}

Water absorption and management of water loss by transpiration are especially important to the survival and growth of species in water-limited environments (Kozlowski et al. 1991). For this reason, functional strategies of drought resistance developed by species in the context of multiple stress factors have been the subject of many studies (Levitt 1980; Larcher 1995). These drought strategies and functional mechanisms to resist water stress have a significant impact in regard to xylem cavitation. Drought resistance strategies fall into two main groups: avoidance mechanisms (Drought avoidance) and tolerance mechanisms (Drought tolerance) (Levitt 1980; Kozlowski et al. 1991; Jones 1992; Larcher 1995). These strategies rely on the prevalence of specific response mechanisms that allow plants to avoid or tolerate water stress by maintaining an active vegetative state (Table 3.1). Drought avoidance is based on maintaining appropriate hydration of tissues and cells under conditions of water deficiency. Species following this strategy can either reduce water loss by closing stomata early or increase water absorption (e.g. deep root systems). The drought tolerance strategy is promoted by physiological traits that permit continuous water transport, gas exchange or cell survival at low water content, and low water potentials $(\psi)$, such as osmotic adjustment, increased structural reinforcement of the wood (Hacke et al. 2001), decreased vulnerability of xylem to embolism, and the ability of cells (especially meristems) to remain alive.

The third type of resistance would be to avoid or escape stress conditions (Drought escape). Many authors do not consider this strategy to be a true resistance mechanism since it occurs in plants that complete their life cycle before the stress affecting them. However, this group also includes vegetative species that exhibit partial dormancy during the summer, such as summer deciduous or semideciduous species (e.g., Periploca sp, Withania $s p$ ) or some rhizomatous grasses (Stipa sp., Lygeum sp., Brachypodium sp.) (Valladares et al. 2008). Despite the different mechanisms, there is no optimal strategy for water-limited ecosystems and plants develop different mechanisms according to their functional characteristics (Levitt 1980). 
Table 3.1 Drought resistance strategies and main mechanisms involved (elaborated from Levitt 1980; Kozlowski et al. 1991; Jones 1992; Larcher 1995; Valladares et al. 2008)

\begin{tabular}{lll}
\hline Resistance strategy & & Main mechanisms \\
\hline Drought escape & Escape stress conditions & Vegetative dormancy \\
Drought avoidance & Short life-span \\
& Avoidance of stress conditions, & Stomatal regulation \\
& isohydric response & Extensive root systems \\
& & High capacity for water transport \\
& from roots to leaves. \\
& & Small leaves, high leaf mass \\
Drought tolerance & Tolerance to decrease water & Osmotic adjustment \\
& potential, anisohydric response & Cell-wall properties \\
& & Antioxidant systems \\
& & Compatible solutes \\
& & High resistance to xylem \\
& cavitation \\
\hline
\end{tabular}

\subsection{Hydraulic Architecture and Water Transport from Roots to Leaves}

Since plants began to colonize the land, they have had to deal with the challenge of uptaking water and transporting it to distal tissues against gravitational forces. Although water transport is fundamental to the life of terrestrial plants, only some of the basic questions about the functionality of the transporting conduits have been extensively studied, while others still remain unclear (Zwieniecki and Holbrook 2009; Brodersen et al. 2010; Nardini et al. 2011).

\subsubsection{The Ascent of Water}

Water flow from the soil to the atmosphere is analyzed as a process based in the Soil-Plant-Atmosphere continuum, termed SPAC (Huber 1928; Van den Honert 1948) and the tension-cohesion mechanism performs the transport of water through the plant (Dixon and Joly 1895). This theory of water ascent in plants, also called cohesion-tension theory (C-T), was initially explained by Böhm (1893), followed by Dixon and Joly (1895). The C-T theory postulates that the cohesion of water molecules and the tensions generated in the water column are essential to the ascent of water. The rise of xylem sap during transpiration is due to capillary menisci of cell walls being evaporatively depleted by solar heating (Pickard and Melcher 2005). This theory constitutes a physical and analytical explanation of xylem transport in vascular plants (see Steudle 2001; Tyree and Zimmermann 2002). 
According to the SPAC concept, both the cohesion of water molecules and the rigidity of xylem conduits allow a force exerted at one end of the conduits to be transmitted throughout the column to the other end. The $\mathrm{C}-\mathrm{T}$ theory has been questioned several times because direct observations of the water potential of conduits, made with pressure probes (Steudle 1995), do not match the potential measured with a Scholander pressure chamber (Zimmermann et al. 1994; Canny 1995 and 2001) or other methodological approaches (Milburn 1996; Salleo et al. 1996; Wei et al. 1999; Cochard et al. 2000a; Kikuta et al. 2003). This led Canny to propose an alternate theory, "the compensating pressure theory" (Canny 1995). However, other studies have provided evidence to the contrary (Tyree 1997; Steudle 2001). This controversy has elapsed for several years (Stiller and Sperry 1999; Canny 2001; Zimmermann et al. 2004; Angeles et al. 2004). Other theories like the "root pressure" or "the capillary ascension" theories may explain the rise of water in small plants or herbs, but they are limited for explaining the ability of water transport to the top of the tall trees which is achieved by the mechanism explained by C-T theory (Steudle 1995).

The xylem is the tissue specialized in the transport of water from the roots to all parts of the plant. The transport of water through the xylem is produced by two factors: driving force and conductance-or its inverse, resistance (Boyer 1985). The driving force originates in the evaporation in the substomata cavities of the leaves. This evaporation allows the flow of water upward from the roots because it produces a negative hydrostatic pressure (suction tension), which is measured as water potential (Scholander et al. 1965). The other factor, conductance, is inversely proportional to the within-plant resistance to water transport in the xylem. This resistance is due to the friction of water molecules against conduit walls and the resistance of some other structures as perforation plates that connect the xylem conduits. As a result of these two factors (hydrostatic pressure and conductance), the water flow through the xylem conforms to Darcy's Law $(F=k h * \Delta \psi)$, where water flow $(F$, $\left.\mathrm{kg} \mathrm{s}^{-1}\right)$ is a function of the hydraulic conductance $\left(k h, \mathrm{~kg} \mathrm{~s}^{-1} \mathrm{MPa}^{-1}\right)$ and the water potential gradient between the both extremes of the conduit ( $\Delta \psi \mathrm{MPa})$.

Moreover, other theories analogous to Darcy's law have been used to describe water flow in plants, e.g., Ohm's law. In this case, the flow of water in the plant is considered to be a catenary process, where each catena component is viewed as a hydraulic conductance (analogous to an electrical conductance) across which the water flows (analogous to electric circuit; Tyree and Ewers 1991). In the same sense, Hagen-Poiseuille's law has also been applied to analyze the transport of water through xylem conduits, where $K h=(\pi \rho / 128 \eta) \Sigma^{n}\left(d^{4}\right)$, assimilating the conducting elements to a capillary (Tyree and Ewers 1991; Tyree and Zimmermann 2002). This law states that hydraulic conductivity per unit pressure gradient $(K h)$ is proportional to the fourth power of the radius of the conducting element, where $\rho$ is the fluid density, $\eta$ is the coefficient of viscosity, $d$ and $n$ are, respectively, the diameter and the number of the conducting elements. It is worthy to note that pit membrane resistance connecting elements is neglected when referring to Poiseuille's law. At cell level, the passive movement of water is 
described by means of Newton's law $(v=(1 / f) F)$ of motion on the Earth where there is friction (Nobel 1999); where $v$ is velocity of movement $\left(\mathrm{m} . \mathrm{s}^{-1}\right), F$ is the force causing the movement $(\mathrm{N})$, and $f$ is the coefficient of friction $\left(\mathrm{N} \mathrm{s}^{-1}\right)$. Water movement occurs when it moves from one point where it has high energy to another where energy is low.

In the plant, the loss of water vapor at leaf level is controlled by the opening and closing movement of the stomata. This mechanism determines the gas exchange in the leaf and the evaporative flux density (E). This flow from leaves is governed by Fick's law of gas diffusion in the air $\left(E=g_{L}\left(X_{i}-X_{O}\right)\right.$; Tyree and Zimmermann 2002), where $g_{L}$ is the diffusional conductance of the leaf (controlled by stomatal conductance, $\left.g_{s}\right), X_{i}$ is the mole fraction of water vapor at the evaporative surface of the palisade and mesophyll cells, and $X_{0}$ is the mole fraction of water vapor in the ambient air surrounding the leaf.

In summary, the hydraulic architecture of a plant can be regarded as a typical hydraulic system composed of: energy transfer (solar radiation on the leaves), a driving force (transpiration flux), pipes or conducting elements (vascular system), reservoirs (living cells), and regulating systems (essentially, the stomata), whose operation is based on the SPAC concept (see Tyree and Zimmermann 2002; Sperry 1995; Hoolbrook and Zwieniecki 2005).

\subsubsection{Hydraulic Architecture and Water Flow Through the Plant}

The most remarkable aspects of sap ascent are, on the one hand, that water moves through the xylem under tension (negative pressure) and, on the other hand, that all land plants potentially face the same fundamental tradeoff to obtain water efficiently and maintain hydraulic conductivity to protect photosynthesis, while running the risk of drought-induced cavitation. In the whole plant, long-distance transport of fluids occurs mainly through vascular tissues which do not show significant membrane barriers. Yet, living tissues can be the site of intense water flows during transpiration or expansion growth (Sperry 1995; Maseda and Fernandez 2006; Markesteijn et al. 2011). While water flows across leaves through the apoplastic, symplastic, and transmembrane pathways (Steudle and Peterson 1998; Maurel et al. 2008), the relative contributions of these pathways to hydraulic conductance are not well characterized in leaves, and also in roots (Voicu et al. 2009; Shatil-Cohen et al. 2011).

Because of the knowledge of hydraulic architecture has grown over the past years, it is now possible to carry out a better analysis of how hydraulic characteristics has allowed trees to cope with periods of drought in water limited ecosystems. One of the key features are plant segmentation and compartmentalization, i.e., any structural feature that confines xylem cavitation to small, distal, expendable organs in favor of larger and more important organs representing years 


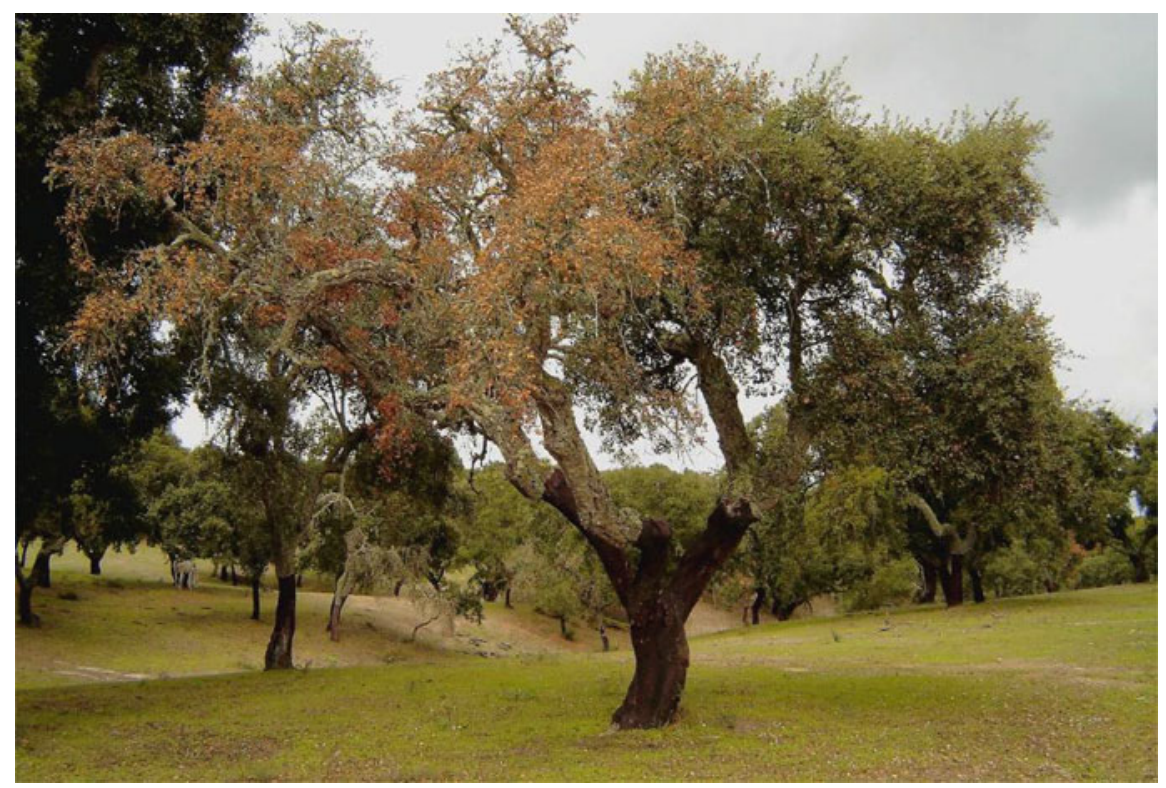

Fig. 3.1 Leaf and branch mortality in a cork oak tree (Quercus suber) after a severe summer drought in the Southeast of Portugal. Almost half of the tree was affected. (Photograph: Vilagrosa)

of growth and carbohydrate investment like trunk and main branches or root system (Tyree et al. 1993; Tyree and Zimmermann 2002; Hölttä et al. 2009). Furthermore, distal and expendable structures due to a large gradient of xylem water potential in shoots were found to be more vulnerable to cavitation in Acer saccharum and Juglans regia stems (Tyree et al. 1993; Tyree et al. 2003, Fig. 3.1). By analyzing the hydraulic architecture and loss of hydraulic conductivity in some seedlings of Mediterranean species under drought stress, hydraulic segmentation and compartmentalization of xylem cavitation and embolisms was found even in early stages of development. This segmentation matches leaf abscissions observed after severe drought conditions (Vilagrosa 2002; Vilagrosa et al. 2003, Fig. 3.2). This kind of plant segmentation is termed vulnerability segmentation. Nevertheless, under drought conditions where stomata remain closed all day long, transpiration will be very low and hydraulic segmentation will be ineffective because water potential will be nearly the same everywhere in the plant from the roots to the shoot tips (Tyree et al. 1993). Although the basic mechanisms of plant hydraulic architecture are fairly well understood, little is still known about how hydraulic properties are related to species' life-history strategies, such as drought and shade tolerance (Tyree and Ewers 1991; Markesteijn et al. 2011).

Plant species rely on different strategies to adapt to the water stress caused by drought spells. Among these strategies is the development of resilient xylem structures that support continuous water transport from roots to leaves (Hacke et al. 2001; Tyree and Zimmermann 2002; Maseda and Fernandez 2006), along 

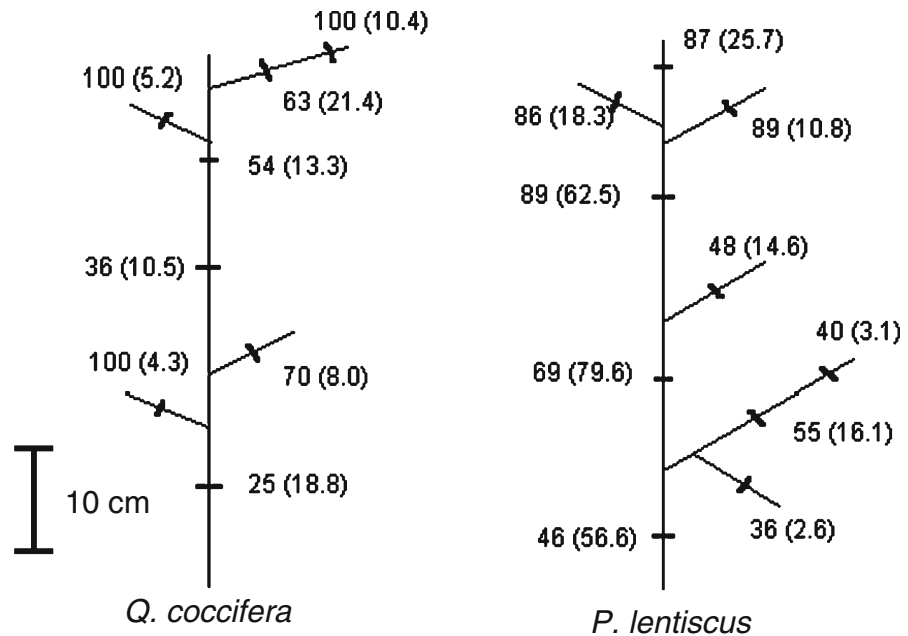

Fig. 3.2 Hydraulic diagrams for saplings of two Mediterranean species (kermes oak, Quercus coccifera, and mastic tree, Pistacia lentiscus) with percentage of cavitation (values outside brackets) and hydraulic conductivity (values inside brackets, LSC $10^{-5}, \mathrm{~kg} \mathrm{~m}^{-1} \mathrm{~s}^{-1} \mathrm{MPa}^{-1}$ ). Both species were in their early stages of development ( 3 years old and about $50 \mathrm{~cm}$ in height). In Q. coccifera, water potential was $-7.0 \mathrm{MPa}$ with an average of $75 \%$ loss conductivity. For $P$. lentiscus, water potential was $-5.9 \mathrm{MPa}$ with an average of $65 \%$ loss conductivity (Vilagrosa 2002)

with water channels at both ends of the water pathway. Indeed, Brodribb and Cochard (2009) demonstrated the role that stem and leaf hydraulics play in determining the drought tolerance of conifers, but they did not consider the role of aquaporins at both root and shoot level. Aquaporins are membrane channels that have a conserved structure and facilitate the transport of water and/or small neutral solutes (urea, boric acid, silicic acid) or gases (ammonia, carbon dioxide). Recently, (Cochard et al. 2007; Kaldenhoff et al. 2008) reported that aquaporins play a central role in plant water relations since they mediate the regulation of root water transport in response to a variety of environmental stimuli. Moreover, aquaporins are also shown to contribute significantly to water uptake by roots. For example, Javot and Maurel (2002) reported that mercury inhibits root hydraulic conductivity by $30-90 \%$ in more than 10 plant species. Moreover, different approaches have established that aquaporins contribute significantly to the permeability of plant membranes in the leaves (Sack et al. 2004; Nardini et al. 2005; Cochard et al. 2007). Although, they facilitate water transport through internal leaf tissues during transpiration and in expanding tissues, their contribution to leaf water transport is still insufficiently understood (Maurel et al. 2008).

Impact of tree height on plant hydraulics remains a hanging question in this area of research (Spicer and Gartner 1998; Koch et al. 2004; Netting 2009). Spicer and Gartner (1998) studied mechanical properties of wood and they suggested that xylem formation represents a tradeoff between mechanical support and an efficient 
supply of water to leaves. In this sense, Spicer and Gartner (1998) analyzed the potential tradeoff between hydraulic and mechanical xylem functions by relating the branch hydraulic properties as consequence of changes in xylem anatomy due to the compression wood. Using branch segments of Douglas-fir (Pseudotsuga menziesii) they found that lower branch halves had significantly lower specific conductivity, higher specific gravity, lower water content and larger proportions of volume occupied by both cell wall and air than upper parts (halves) of the same branch. These differences in hydraulic properties between upper and lower halves suggested that compression wood, evidenced by the changes in the xylem anatomy, does reduce xylem transport efficiency (Spicer and Gartner 1998). However, other studies (Spicer and Gartner 2002) report that seedlings affected by compression wood maintained the same water potentials and stomatal conductance than controls seedlings. Finally, these authors conclude that reductions in stem specific conductivity, caused by compression wood, have a little impact on leaflevel processes when the entire soil-plant-atmosphere continuum is considered.

Later, some reports (Koch et al. 2004) indicate that tree height is limited by water transport constraints in taller trees which induce reductions in leaf net assimilation rate through stomatal regulation. Koch et al. (2004) observed that the tallest trees (i.e. higher than $120 \mathrm{~m}$ ) are prone to an irreversible loss of hydraulic conductivity because of conduit embolisms when their xylem pressure decreases to values less than $-1.9 \mathrm{MPa}$. They conclude that the maximum height is $122-130 \mathrm{~m}$ for Sequoia sempervirens originated from northern California. Moreover, they also observed an increase in stable carbon isotope composition $\left(\delta^{13} \mathrm{C}\right)$ and in leaf mass to area ratio for the higher parts of the trees as well as a decrease in leaf photosynthesis rates. Netting (2009) questioned these results because embolism-repair mechanisms may occur by $-2.7 \mathrm{MPa}$ and concludes that tree height may be limited by a long-term balance between dieback and sustained growth.

\subsubsection{Changes in Hydraulic Architecture in Response to Different Processes}

Previous sections defined hydraulic architecture in terms of the characteristics of the water-conducting structure of plants, such as design and hydraulic functions, and other related variables such as conductivity, porosity, and vulnerability (Tyree and Zimmermann 2002). Additional properties derived from these hydraulic variables, such as hydraulic segmentation and vulnerability segmentation, are also analyzed in hydraulic architecture studies. On the one hand, the aboveground shoot hydraulic architecture is associated with crown design: the vertical position of the branches within a crown affects both the morphologic and the physiological acclimation of the crown for light acquisition and hydraulic conductance (Yoshimura 2011). On the other hand, the root hydraulic architecture is also affected by the length, segmentation, and development of the root system among 
other variables. Considering that hydraulic architecture determines the capacity to supply all the plant parts with water, we will analyze the hydraulic architecture and its relationship to different plant processes such as regulation of transpiration, plant functional types, and how some abiotic conditions can change root hydraulic conductivity in this section.

\subsubsection{Hydraulic Architecture, Water Availability, and Gas Exchange}

Several studies related the hydraulic architecture of the xylem network to other plant processes like water availability or instantaneous gas exchange rates (Sperry 2000; Nardini and Salleo 2000; Hubbard et al. 2001). Changes in hydraulic architecture may affect water use efficiency (WUE) at leaf level and water potential gradient at the whole plant level (Brodribb and Holbrook 2003). Under conditions of high water demand, $P$. lentiscus seedlings with high root hydraulic conductance showed an increase in transpiration $(E)$ without increasing the water potential gradient between soil and leaves (Hernández et al. 2009). In general, plants living in reduced water availability conditions produce changes in their xylem network such as increased hydraulic conductance to provide a better supply of water to leaves (Jacobsen et al. 2007a; Martínez-Vilalta et al. 2009).

Water transport is essential for carbon fixation and gas exchange in land-based plants. Coordination between hydraulic architecture and control of gas exchange at leaf level, expressed as transpiration $(E)$, net $\mathrm{CO}_{2}$ assimilation $(A)$, and stomatal conductance $\left(g_{s}\right)$, may also be related to the life-history features of a species. In this sense, the relationship between photosynthesis and leaf-specific hydraulic conductivity reflects a balance between carbon gain and water transport capacity. A study of 11 species in a preAlpine continental climate showed that shoot hydraulic conductance limited the maximum stomatal conductance (Nardini and Salleo 2000). These authors observed that species with lower maximum stomatal conductance had proportionally lower shoot hydraulic conductance than species with a higher water demand. Another study (Santiago et al. 2004) in a tropical area (annual rainfall $1800 \mathrm{~mm}$ ) reported that the leaf-specific hydraulic conductivity $\left(k_{\mathrm{L}}\right)$ of upper branches was positively correlated with maximum rates of net $\mathrm{CO}_{2}$ assimilation per unit leaf area $\left(A_{\text {area }}\right)$ and stomatal conductance $(g s)$ across 20 species of canopy trees. Moreover, maximum $k_{\mathrm{L}}$ showed a stronger relationship with $A_{\text {area }}$ than with initial $k_{\mathrm{L}}$ suggesting that the assignment to photosynthetic capacity is proportional to maximum water transport capacity (Santiago et al. 2004). For seven co-occurring Mediterranean species (Anthyllis cytisoides L., Genista scorpius L. DC., Myrtus communis L., Pistacia lentiscus L., Rosmarinus officinalis L., Spartium junceum L. and Ulex parviflorus Pour.), Hernandez et al. (2010) found a positive correlation between leaf gas exchange variables and root hydraulic conductance scaled by stem cross-section area $\left(K_{\mathrm{As}}\right)$. These authors indicated that species with high specific root length (SRL) show high $K_{\text {As }}$. These patterns suggest that root system morphology determines both leaf gas exchange 
and root capacity for water transport. Adaptations in hydraulic design may differ considerably across species. Some of species' responses show a phylogenetic signal while others respond to functional syndromes or plant functional traits (Jacobsen et al. 2008). Indeed, Hernández et al. (2011) observed that Mediterranean species with different regenerative strategies after wildfires, i.e., seeder and resprouter species, showed contrasted patterns of hydraulic architecture and gas exchange, independent of phylogenetic affiliation patterns.

\subsubsection{Effects of Nutrients and Light Availability}

The general principle governing resource acquisition in response to stress is that plants allocate resources preferentially to functions that most strongly limit growth (Chapin 1991). Nitrogen, phosphorous and potassium fertilization significantly affects several components of hydraulic architecture, including cavitation resistance (Harvey and Van den Driessche 1997; Ewers et al. 2000; Trubat et al. 2006). Leafspecific hydraulic conductance was reduced by $50 \%$ in fertilized trees of Pinus tadea (in contrast to other treatments, including the control treatment), due to a higher leaf area per sapwood area and lower specific conductivity of plants and root xylem (Ewers et al. 2000). Moreover, specific conductivity of terminal stems increases with $\mathrm{N}$ supplies, whereas leaf-specific conductivity and wood density decreases (Bucci et al. 2006). Overall, fertilization treatments can change the root hydraulic conductance of seedlings, but the response is species-dependent. Hernandez et al. (2009) indicated that a high fertilization treatment increased the leaf area and root biomass of $P$. lentiscus seedlings, but reduced the values of root hydraulic conductance on a leaf area basis $\left(K_{R-L A}\right)$. Seedlings cultivated under low fertilization showed values of $K_{R-L A}$ around $34.0 \pm 7.9 \mathrm{~kg} \mathrm{~m}^{-2} \mathrm{~s}^{-1} \mathrm{MPa}^{-1} \times 10^{-5}$ while under high fertilization values were around $9.2 \pm 1.8 \mathrm{~kg} . \mathrm{m}^{-2} \mathrm{~s}^{-1} \mathrm{MPa}^{-1} \times 10^{-5}$. Similar results to those previously reported for P. lentiscus were also observed for morphologic traits and root hydraulic conductance in Pinus canariensis (Luis et al. 2010). In this study, pine seedlings grown at full sunlight under high fertilization conditions showed lower $K_{R-L A}$ than those treated with low fertilization doses $\left(K_{R-L A}\right.$ was $4.9 \pm 1.0$ and $1.3 \pm 0.5 \mathrm{~kg} \mathrm{~m}^{-2} \mathrm{~s}^{-1} \mathrm{MPa}^{-1} \times 10^{-5}$ for low and high fertilization treatments, respectively). Hydraulic conductivity in roots of Fraxinus pennsylvanica was positively correlated with P concentration (Andersen et al. 1989), and an increased P supply reduced cavitation in the xylem of hybrid poplars as a result of conduit modifications (Harvey and Van den Driessche 1997).

Nutrient deficiency also affects plant morphology and root hydraulics (Ewers et al. 2000; Williamson et al. 2001, Bucci et al. 2006). In P. lentiscus (L.), Trubat et al. (2006) observed that nitrogen deficiency decreased aboveground biomass accumulation and leaf area, but did not affect below-ground biomass accumulation and root morphology. Phosphorus-deficient plants showed a decrease in leaf area and an increase in root length, root surface area, and SRL. Consequently, nitrogen and phosphorus deficiency reduced the root hydraulic conductance scaled by total root surface area $\left(K_{R-R S}\right) . K_{R-R S}$ in control seedlings was $1.3 \pm 0.2 \mathrm{~kg} \mathrm{~m}^{-2} \mathrm{~s}^{-1} \mathrm{MPa}^{-1} \times 10^{-5}$ 
while in seedlings treated with deficiency of nitrogen and phosphorus was $0.8 \pm 0.2$ and $0.6 \pm 0.0 \mathrm{~kg} \mathrm{~m}^{-2} \mathrm{~s}^{-1} \mathrm{MPa}^{-1} \times 10^{-5}$, respectively. These authors also observed that root conductance per unit leaf area was not affected by treatments and concluded that low nutrient availability did not affect seedling capacity for maintaining water supply to leaves due to differences in root system development. Besides, Lovelock et al. (2006) found that plants grown on a P-deficient site showed lower leaf water potential, stomatal conductance and photosynthetic carbon-assimilation rates, and less conductive xylem, than plants on an N-limited site. These differences were markedly reduced when $\mathrm{P}$ fertilization was applied to the $\mathrm{P}$-limited site. In contrast, fertilization with $\mathrm{N}$ on the $\mathrm{N}$-limited site had little effect on either photosynthetic or hydraulic traits.

The concentration of cations in the xylem sap can alter the xylem water flow in angiosperm plants. Recent evidence of ion-mediated changes in pit membrane porosity suggests that plants should modulate hydraulic conductance (Cochard et al. 2010; Nardini et al. 2010) because the sap ionic composition has a strong effect on the xylem hydraulic conductance of a large number of species (Zwieniecki et al. 2001; Cochard et al. 2010). The current interpretation of this phenomenon is attributed to both the porous structure and the high pectin content of interconduits pit membranes (Nardini et al. 2007; Jansen et al. 2011) while other studies invoke the shrinking of some king of polyelectrolyte polymers as the result of electrostatic events (van Doorn et al. 2011). Herbette and Cochard (2010) brought up the regulating role of calcium in cavitation resistance of trees. For these authors, removing calcium from the stem-cell wall leads to an increase in xylem vulnerability to cavitation without impairing the xylem hydraulic conductance. As vulnerability to cavitation relied on pit membranes conduits, their structure made of hemicelluloses, and pectins should play a major role (Hafren et al. 2000; Willats et al. 2001).

Light availability is known to affect several morphological and functional plant traits (Valladares and Pearcy 1998). The effect of sunlight on hydraulic characteristics and vulnerability to cavitation was found to vary with light availability and environmental conditions. Low light availability altered the hydraulic design and produced higher vulnerability to cavitation in branches of Fagus sylvatica trees (Cochard et al. 1999; Barigah et al. 2006; Herbette et al. 2010). In contrast, in some Mediterranean species, shading treatments did not produce significant differences at root level e.g., changes in root hydraulic conductance in some Mediterranean species (Hernández et al. 2009; Luis et al. 2010). Light availability produce changes in stem hydraulic conductance $\left(K_{\text {stem }}\right)$ which can be related with changes in the ionic concentration in the xylem sap (Nardini et al. 2010). Field measurements on Laurus nobilis revealed that sun-exposed branches had $60 \%$ higher $K_{\text {stem }}$ with respect to shade-exposed branches. Nardini et al. (2010) linked these results to higher xylem sap potassium concentration in the sun-exposed branches. The authors indicated that this ionic effect (high potassium concentration) is apparently a mechanism of plants to decrease the hydraulic resistance in the illuminated branches, thus diverting water flows toward sun-exposed foliage, preventing leaf dehydration, and favoring stomatal aperture and high rates of photosynthesis. 
Fig. 3.3 Morphologic variability in the root systems of Quercus ilex L. of the same age subjected to different rooting environments. Left, seedling grown in a $100 \mathrm{~cm}$ deep container; right, seedling grown in a $20 \mathrm{~cm}$ deep container. (Photographs: Pemán)
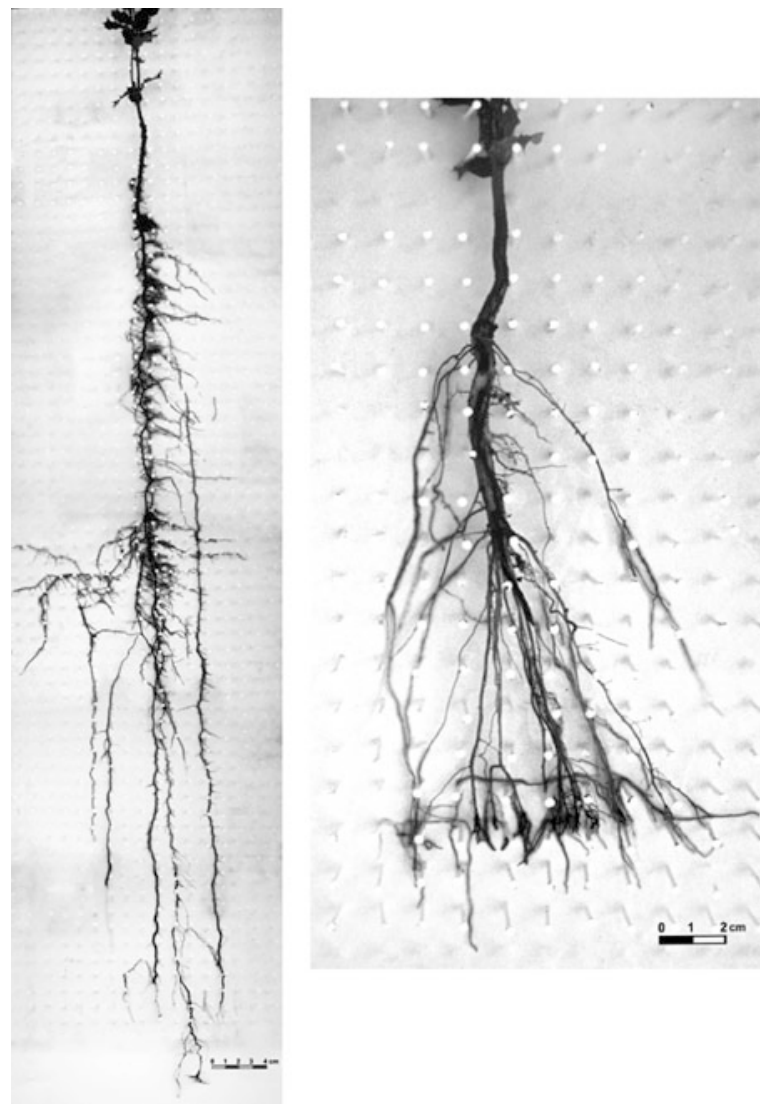

\subsubsection{Effects of Root Development}

A plant's capacity to transport water from soil to leaves is highly dependent on its root architecture. Morphologic root features vary among species and are significantly correlated with root hydraulic conductance and leaf gas exchange variables, such as transpiration, net $\mathrm{CO}_{2}$ assimilation and stomatal conductance (Addington et al. 2006; Peman et al. 2006; Chirino et al. 2008). A study carried out by Chirino et al. (2008) showed that the nursery cultivation of $Q$. suber seedlings in deep containers CCL-30 (depth: $30 \mathrm{~cm}$, diameter: $5 \mathrm{~cm}$; volume: $589 \mathrm{~cm}^{3}$ ) improves the morpho-functional attributes related to root growth and functionality as compared to seedlings cultivated in standard containers. Similar results were reported by Pemán et al. (2006) who compared the functionality of root systems differing in size and shape (Fig. 3.3). The use of deep containers led to produce seedlings with a long tap root able to reach deeper soil horizons by means of higher growth in biomass and number of new roots. In this sense, deep containers 

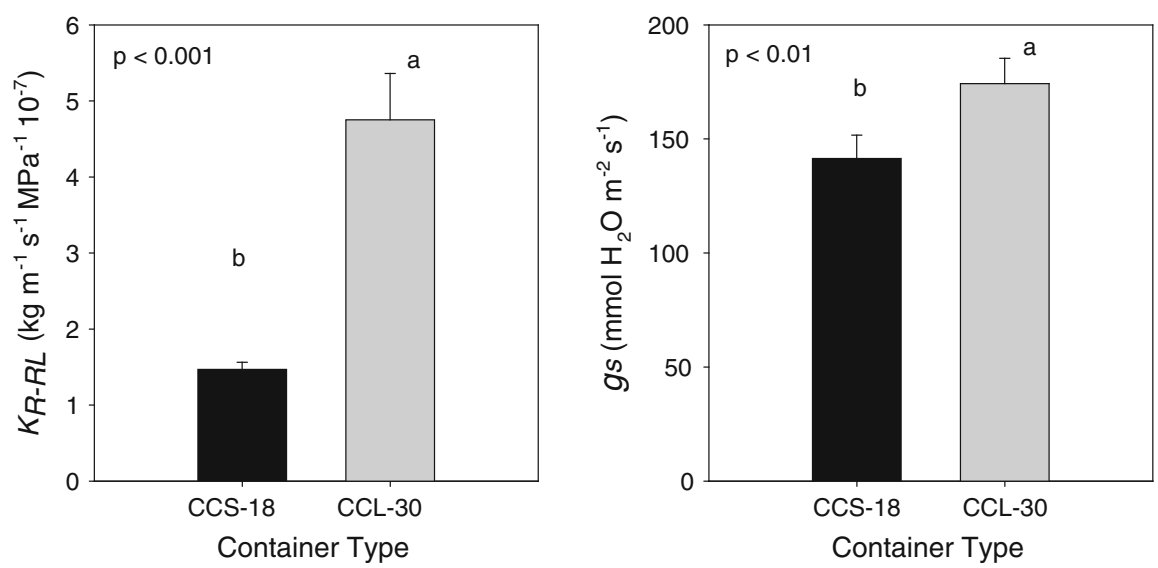

Fig. 3.4 Root hydraulic conductance per root unit length $\left(K_{R-R L}\right)$ and maximum stomatal conductance (gs) in seedlings cultivated in standard containers (black bars, CCS-18; depth: $18 \mathrm{~cm}$, diameter: $5 \mathrm{~cm}$; volume: $300 \mathrm{~cm}^{3}$ ) and in deep containers (gray bars, CCL-30; depth: $30 \mathrm{~cm}$, diameter: $5 \mathrm{~cm}$; volume: $589 \mathrm{~cm}^{3}$ ). Different letters indicate significant differences at $P<0.05$

Fig. 3.5 Mean vessel diameter for seedlings of Quercus coccifera seedlings grown in both types of containers (the same as in Fig. 3.4). Differences between the two groups of seedlings were statistically significant $(\mathrm{P}<0.05)$

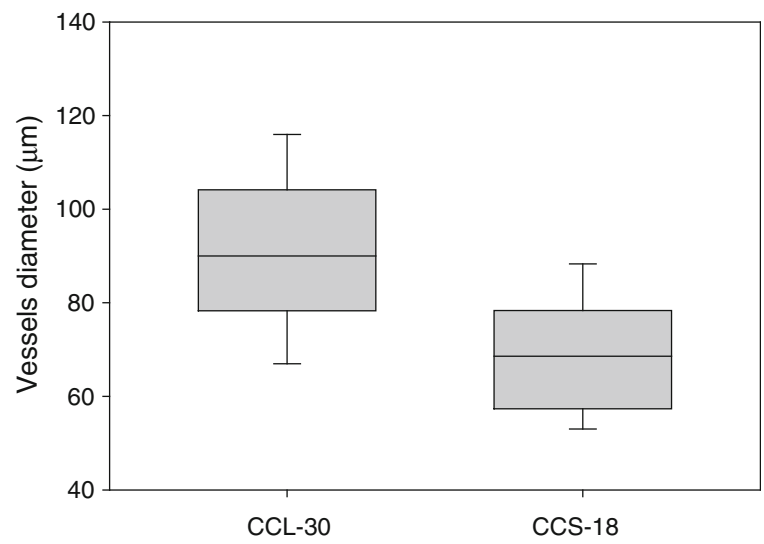

favored a high water transport capacity, expressed as root hydraulic conductance scaled by leaf area or root length (Fig. 3.4 Left) or also accounted for changes in vessel size (Fig. 3.5). These morpho-functional advantages contributed to a better water status under drought stress conditions as brought up by in higher stomatal conductance values (Chirino et al. 2009; Fig. 3.4 Right). Therefore, root characteristics as rooting depth, biomass, and xylem conduits can increased the plant hydraulic efficiency to supply water to leaves. 


\subsection{Xylem Cavitation and Embolism}

As pointed out above, sap is transported under tension (i.e. negative pressure) according to the tension-cohesion theory. When the water tension inside the conduits is too negative, the breakage of the water column can occur, a phenomenon known as xylem cavitation (Tyree and Sperry 1989; Tyree and Zimmermann 2002). Embolism results from this phenomenon and rises in plants as a consequence of either by water stress (Tyree and Sperry 1989) or freeze-thaw cycles during winter (Sperry and Sullivan 1992). This phenomenon can cause a substantial reduction in xylem water transport and thus exerts a debilitating influence on plant water status by decreasing its hydraulic conductance. Thus, plants can no longer provide water properly to leaves and other tissues.

In relation to water stress induced cavitation, several mechanisms have been postulated for the formation or entry of air bubbles in the xylem conduits (see Tyree et al. 1994 for a review of all mechanisms), but the most commonly accepted mechanism is the "air seeding" postulated by Zimmermann and Crombie (Jarbeau et al. 1995; Salleo et al. 1996; Tyree and Zimmermann 2002). According to that mechanism, cavitation occurs when an air bubble outside a water-filled conduit is aspirated into the xylem element through pit pores as a consequence of the tension. In addition, Sperry and Saliendra (1994) showed that the vulnerability of the xylem to cavitation increased with enhancing the permeability of the pores after altering the surface tension of the xylem sap. The small size of the pores in the pit membranes prevents the air entry from an embolized xylem element to another functional conduit until the pressure gradient exceeds a certain threshold. This threshold depends on the radius of the pore. When the tension rises, the water potential becomes more negative, and suction from the air embolized xylem conduits occurs, creating a meniscus. If the meniscus radius equals the pore radius, air bubbles will be suctioned in. This is expressed by the formula:

$$
\psi_{x}=-2 \tau \cos a / r_{m}
$$

where $\psi_{x}$ is the difference between the critical pressure potential of xylem and air pressure to move the gas meniscus in the pore and thus match the radius of the meniscus $\left(\mathrm{r}_{\mathrm{m}}\right)$ to the radius of the pores in the pit membrane. $\tau$ is the surface tension of water $\left(0.072 \mathrm{~Pa} \mathrm{~m}\right.$ at $\left.25^{\circ} \mathrm{C}\right)$ and " $\mathrm{a}$ " is the contact angle between the meniscus and the pore (Tyree and Sperry 1989).

Therefore, cavitation resistance depends on the size of the largest pores in the pit membranes in angiosperms. In gymnosperms, inter-tracheid pits are quite different in structure and function from inter-vessel angiosperm pits (Tyree and Zimmermann 2002). The mechanism of "air seeding" in gymnosperms would be somewhat different due to special characteristics of pits (Tyree and Zimmermann 2002). Pit membrane porosity and characteristics of torus and margo structures are involved in cavitation resistance (Sperry and Tyree 1990; Tyree and Zimmermann 2002). Three mechanisms have been proposed in conifers: (1) a rupture of pit margo microfibrils, (2) a displacement of the pit torus from its normal sealing 
position over the pit aperture, and (3) a rupture of an air-water menisci in a pore of the pit margo (Sperry and Tyree 1990; Cochard 2006; Pittermann et al. 2006; Cochard et al. 2009). The first studies pointed out that cavitation could then occur by elastic stretching of the margo or by rupture of the microfibril strands (Sperry and Tyree 1990). Pittermann et al. (2010) examined pit structure in 15 species of Cupressaceae exhibiting a broad range of cavitation resistances. These authors observed that cavitation resistance was most closely correlated to the ratio of the torus to pit aperture diameter and they suggested that impermeable torus has the capacity to exert a valve effect by sealing the pit aperture as consequence of xylem tensions during drought. Other studies suggested that cavitation in conifers could also be provoked by the capillary failure of an air-water meniscus located between the torus and the pit wall aperture because of they found a linear relation between sample vulnerability to cavitation and fluid surface tension (Cochard 2006, 2009). This mechanism could rather be similar to the mechanism proposed for angiosperms. Recently, Delzon et al. (2010) observed in 40 conifer tree species that high cavitation resistance exhibited both a high flexibility of the margo and a large overlap between the torus and the pit aperture, allowing the torus to tightly seal the pit aperture. These results support the hypothesis of seal capillary-seeding as the most likely mode of air-seeding, and suggest that the adhesion of the torus to the pit border may be the main determinant of cavitation resistance in conifers (Delzon et al. 2010).

\subsubsection{Methodologies for Measuring Xylem Cavitation and Embolism}

One of the oldest methods for detecting cavitation is the acoustic registration of the cavitation event, both in the audible (Low-Frequency) range (Milburn and Johnson 1966; Crombie et al. 1985) and in the ultrasonic range (Tyree et al. 1984). The rapid relaxation of the tension in the liquid (xylem water) or in the solid components of the conductive tissues would explain the audio and ultrasonic emission respectively (Tyree and Sperry 1989; Lo Gullo and Salleo 1991). This method has been used in many studies for recording cavitation events in stems (Tyree and Sperry 1989; Mayr and Sperry 2010) or leaves (Salleo et al. 2001; Trifilo et al. 2003). A critical analysis of the advantages and disadvantages of registering acoustic emissions as a technique for detecting cavitation and interpreting its effects in plant hydraulics can be found in Jackson and Grace (1996). As a main conclusion, these authors consider the method useful for defining water potential threshold values for cavitation in order to explain differences in drought tolerance among individuals or species. They also considered that it has only a limited use while calculating the amount of hydraulic conductivity loss registered at the different water potential values. 
Fig. 3.6 Transverse section of Pistacia lentiscus stem stained with basic fuchsine. Functional vessels were stained in red while nonfunctional vessels remained unstained (right). Photograph: Vilagrosa

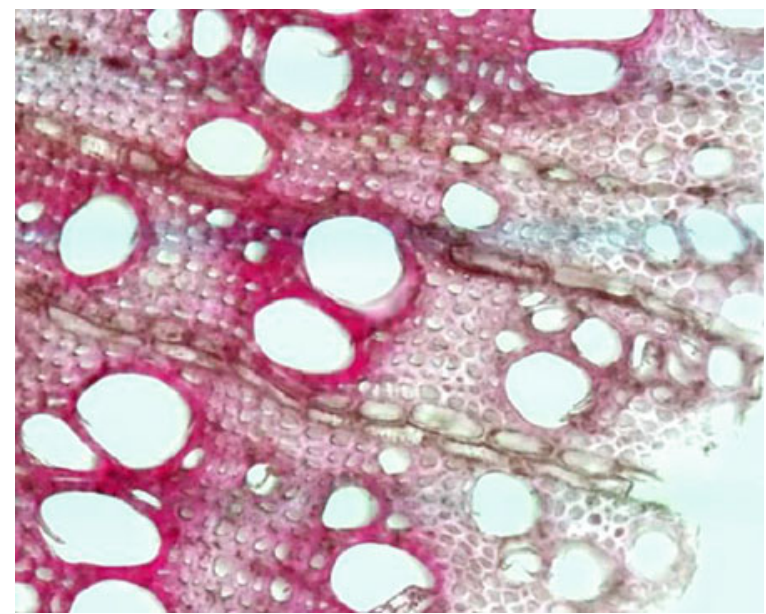

Anatomic methods have also been useful for the study of xylem cavitation. The oldest procedure is based on the perfusion of a sample at low pressure with a dye like safranin, basic fuchsin, alcian blue, phloxine B (Lo Gullo and Salleo 1991; Peguero-Pina et al. 2011a). This method implies a microscopic observation of a previously perfused segment for an accurate distinction between embolized and non-embolized conduits (Corcuera et al. 2006). This allows visualizing the water conducting cross-sectional area of the sample (Fig. 3.6). The use of cryo-scanning electron microscopy enables highly accurate distinctions between water- and airfilled conduits (Cochard et al. 2000) or tracheids (Mayr and Cochard 2003; Cochard et al. 2004). This method brings up directly the presence of water in the conduits is directly confirmed. However, the relative complexity of the sampling procedure and the cost of the required equipment represent a clearly a limitation for its extensive use.

The 'hydraulic' method relies on a conductivity apparatus devised by Sperry et al. (1988). It constitutes the main reference for quantifying xylem embolism and the method consists in estimating the hydraulic conductance of a stem segment before and after successive perfusions under pressure with degassed and filtered $(0.10-0.22 \mu \mathrm{m})$ water solution to measure the initial conductivity, assuming that the possible embolism in open vessels or tracheids has not been displaced. The perfusion evacuates or dissolves air contained in the embolized xylem conduits. The initial to final conductivity ratio gives a quantitative value of embolism level i.e., the related percent loss conductivity (PLC). The percentage of initial hydraulic conductivity related to the maximum one is an estimation of the amount of embolism.

The apparatus allows to assess the hydraulic conductivity in stem (Lo Gullo and Salleo 1991), root (Alder et al. 1996) and petiole segments (Cochard et al. 2000a). This technique (Fig. 3.7) is now widespread but remains laborious and delicate since it requires the use of a precision balance (it is unusable in the field) and the focused plant material requires being connected to a water-filled tubing system to 


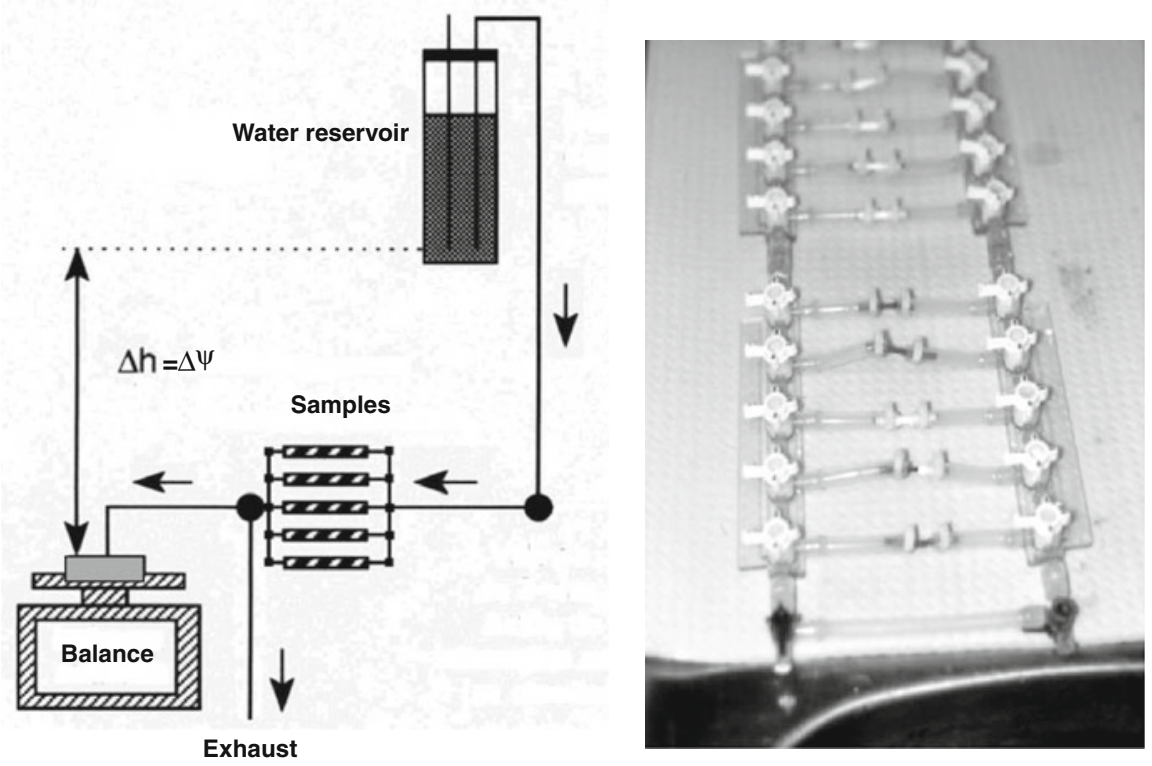

Fig. 3.7 Hydraulic method for embolism determination as designed by Sperry et al. (1988). Left, schematic representation of the hydraulic system. The water is allowed to flow at low pressure from the water reservoir to the balance through a water-filled tubing system and each plant material. The pressure gradient is determined by the difference in height between the balance and the water reservoir. After the initial measurement, the whole hydraulic system is flushed at high pressure to remove any embolisms. Right, a photograph of the plant material (stem segments) connected to the tubing system through which water flows from the reservoir to the balance

be perfused at low pressure (up to $10 \mathrm{kPa}$ ) and high pressure (100-175 $\mathrm{kPa}$ ). Recently, an improved version of the Sperry's apparatus (Xyl'EM, xylem embolism meter) was designed (Cochard et al. 2000b). It measures the water flows with a high precision liquid flowmeter (Liquiflow, Instrutec, France) instead of an accurate balance. Thus, easy and fast measurements can be performed in the laboratory as well as in field with the Xyl'EM. Another variation of the method proposed by Sperry et al. (1988) can be found in Spicer and Gartner (1998), Mayr and Cochard (2003). In this procedure, a 'Micro-Sperry apparatus' was used, which allows the perfusion of small areas of the xylem by using steel cannulas inserted in the wood of a branch segment.

Different solutions have been used to prevent the microbial proliferation that induces a long-term decline in conductivity due to the clogging of the conduits (Sperry et al. 1988). Among these are oxalic (Sperry et al. 1988; Spicer and Gartner 1998), citric (Jarbeau et al. 1995) or hydrochloric acid (Kolb et al. 1996; Vilagrosa et al. 2003), KCl solutions (Lo Gullo and Salleo 1991) and, more recently, commercial silver biocides (Mayr and Cochard 2003; Peguero-Pina et al. 2011b). The low flows through the stem have to be registered as a mass flow with a digital balance (LoGullo and Salleo 1991; Vilagrosa et al. 2003) or a high 
precision liquid mass flowmeter (Cochard et al. 2000b). In more complex structures, the methods for measuring embolism have to be adapted to overcome the difficulties associated with the features of the sample, although the basic principle-perfusion before and after embolism dissolution with carefully prepared solutions-is maintained. Kolb et al. (1996) designed a setup for branched systems, such as whole shoots and roots. For this purpose, the shoot and most root tips are previously cut off before being enclosed in a vacuum chamber. The use of vacuum allows the establishment of pressure differences, inducing a flow of the solution through the complex system while minimizing the risk of refilling the potentially embolized conduits. The hydraulic conductance is then determined from the slope of the linear relationship between the flow rate and the different vacuum pressures applied.

The hydraulic method is the most widely developed technique for measuring the different degrees of water stress in plant, shoot, or root segments. Initially, to reach different levels of water stress, dehydration was applied by means of drying out the samples. The water potential of samples was determined by psychrometric or pressure chamber techniques. Later, negative water potentials were reached by applying plants organs to positive potentials in a Scholander chamber (Cochard et al. 1992). The reduction in hydraulic conductivity in relation to the applied pressure showed similar results to those found with the dehydration method (Cochard et al. 1992; Sperry and Saliendra 1994). From these results, the air injection methodology was developed (Sperry and Saliendra 1994). In this method, the branch or root segment is introduced into a pressure chamber with both ends open. This allows access to both ends of the branch to be measured. The hydraulic conductivity is measured with the segments exposed to increases in pressure within the chamber.

Nowadays, the centrifugation method is one of the most used which generates negative water potentials in shoot and root segments (Alder et al. 1996). The main advantage of this method is its ability to handle more samples per unit of time, while the drawbacks are the requirements of an ultracentrifuge and a customized rotor. Currently, this method has undergone several transformations in order to make determinations in shorter periods of time (see Alder et al. 1996; Cochard et al. 2005; Li et al. 2008 for detailed information), including ultracentrifuges in which the hydraulic conductivity of stem segments is directly measured (Cavitron method; Cochard et al. 2005). However, certain inconsistencies in the results, especially in species with long vessels, suggest the use of caution while determining vulnerability curve (VC)s to cavitation with these methods (Cochard et al. 2010; Choat et al. 2010; Sperry et al. 2011).

The xylem vulnerability to drought stress-induced cavitation of a tree species is assessed by relating cavitation events to water potential $(\psi)$. It typically consists in plotting PLC values versus $\psi$ (see Fig. 3.10a for examples of vulnerability curves in some Quercus species). The resulting curve is a vulnerability curve . Loss hydraulic conductivity is expressed as percent of maximum stem-segment conductivity. PLC is determined by collecting stem segments previously cut under water and measuring the flow of water through the segment for a given low 
Fig. 3.8 Bubbles coming out from a cavitated stem segment when it is injected with degassed water at high pressure $(0.1 \mathrm{MPa})$. Photograph: Vilagrosa

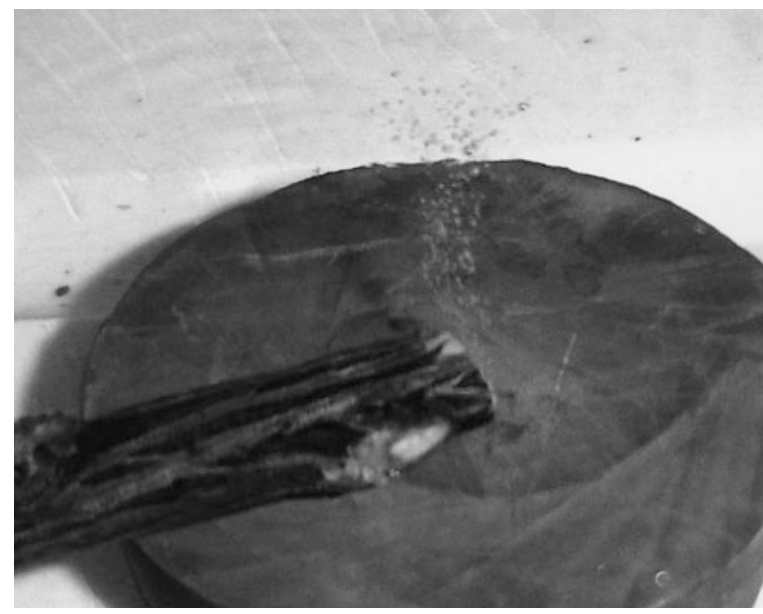

pressure $\left(\mathrm{K}_{\mathrm{i}}\right)$. After this first measure, stem segments are perfused with water to high pressure (typically, at $0.1 \mathrm{MPa}$ ) to remove air from any embolized conduit (Fig. 3.8). Then, the water flow is determined again $\left(\mathrm{K}_{\max }\right)$. PLC is calculated as 100(1 - $\left.\mathrm{K}_{\mathrm{i}} / \mathrm{K}_{\max }\right)$ (Sperry and Tyree 1990).

\subsubsection{Xylem Cavitation in the Context of Plant Functionality: Leaf, Stem, and Root Vulnerability}

The concept of (SPAC) allows us to study the flow of water through plants from the source (soil) to the final sink (atmosphere). Among all the well-defined resistances to water flow (see Black 1979), stomata have traditionally been regarded as the main variable in the regulation of the flow from the plant leaf (Weatherley 1976; Sack and Holbrook 2006). The study of whole plant hydraulic has shown that: (1) stomata are not the only way to regulate the water movement through the SPAC (Luu and Maurel 2005) and (2) the break in the continuum due to embolism in the xylem should induce a shift in the whole resistance to water flow throughout the plant which can result in a critical dysfunction of the vascular transport pathway (Tyree and Cochard 1996; Tsuda and Tyree 2000). The paramount importance of maintaining the values of the different resistances to the movement of water through the xylem has been the theme of many papers since the first decades of the twentieth century (Tyree and Sperry 1989).

The movement through the xylem starts as soon as water has reached the root stele and constitutes one of the most complex mechanisms in the physiology of plant water relations. Effectively, the complexity of the water flow through the root is a reflection of the inherent anatomic complexity of this plant organ (Steudle and Peterson 1998). This affirmation can be better appreciated if an upper scale, the 
architecture of the entire root system, is also computed as an essential feature contributing to the complexity (Peman et al. 2006). In spite of this complexity, significant progress has been made toward understanding and modeling the biophysics and biochemistry of water movement in the roots, both across the nonvascular pathway, i.e., radially from the root surface to the xylem, and across the vascular pathway, i.e., through the xylem toward the demanding areas of the plant (Tyree et al. 1994; North et al. 2004).

The relative importance of root xylem cavitation and embolism in the physiology of the plant is mediated by the contribution, in terms of resistance to the whole plant water, of the non-vascular and vascular pathways, respectively (Huang and Nobel 1993). Frensch and Steudle (1989) proposed that the flow through the non-vascular pathway in small roots is the main resistance element in the entire process. Different studies have shown that this resistance increases when plants are subjected to drought stress, as a consequence of deep anatomic changes (North and Nobel 1992) and/or biochemical, aquaporin-mediated effects (North et al. 2004). Lo Gullo et al. (1998) showed how severe drought stress caused anatomic changes in roots of Olea oleaster, which formed a two-layered exodermis with thicker suberized walls, and a three- to four-layered endodermis with completely suberized tangential walls. In terms of seasonal water relations in Mediterranean plants, such an effect implies that the plant, once its root system is affected, has to recover from these changes by resuming the growth of root tips and producing new lateral roots. The need for reinvestment in the root system after a severe drought should be taken into consideration when analyzing the recovery of physiological activity in Mediterranean woody plants after the summer period (Corcuera et al. 2005).

In spite of the above considerations, the study of vascular pathway resistance in root hydraulics and how it increases as a result of xylem cavitation has been the subject of many papers due to the great importance of this process in the whole plant physiological response to drought. Root xylem properties generally differ from stem ones (McElrone et al. 2004), a fact that has led many researchers to consider that the former may be more tightly linked to the control of the entire water movement in the SPAC (Jackson et al. 2000). Among other differences between root and stem xylem features, roots are generally more vulnerable to xylem cavitation than stems (Sperry and Saliendra 1994, Alder et al. 1996, Hacke and Sauter 1996; Jackson et al. 2000). These results suggest that they may be the weakest link along the soil-to-leaf water transport pathway (Martínez-Vilalta et al. 2002; McElrone et al. 2004, Fig. 3.9). Therefore, incorporating information on the hydraulic properties of roots in addition to that of stems in comparative studies may help identify adaptive relationships between xylem function and other physiological traits (Maherali et al. 2006).

Since the first papers on xylem cavitation (Tyree and Sperry 1989), the studies of the integrity of stem conductivity at different water stress levels have served as a way of explaining niche segregation among closely related (Tyree and Cochard 1996; Hao et al. 2008) or congeneric species (Tognetti et al. 1998; Vilagrosa et al. 2003). Figure 3.10 shows the different performances in terms of vulnerability to water stress induced cavitation among different Quercus species covering a wide 
Fig. 3.9 Comparison of the water potential at $\mathrm{PLC}_{50}$ (50 \% loss of hydraulic conductivity) between roots and shoots for 24 species. Methods for induced cavitation were dehydration, air injection, and centrifugation. (From:

Martínez-Vilalta et al. 2002; Oliveras et al. 2003; Stout and Sala 2003, McElrone et al. 2004; Pratt et al. 2007; Froux et al. 2005; Hukin et al. 2005; Domec et al. 2006)

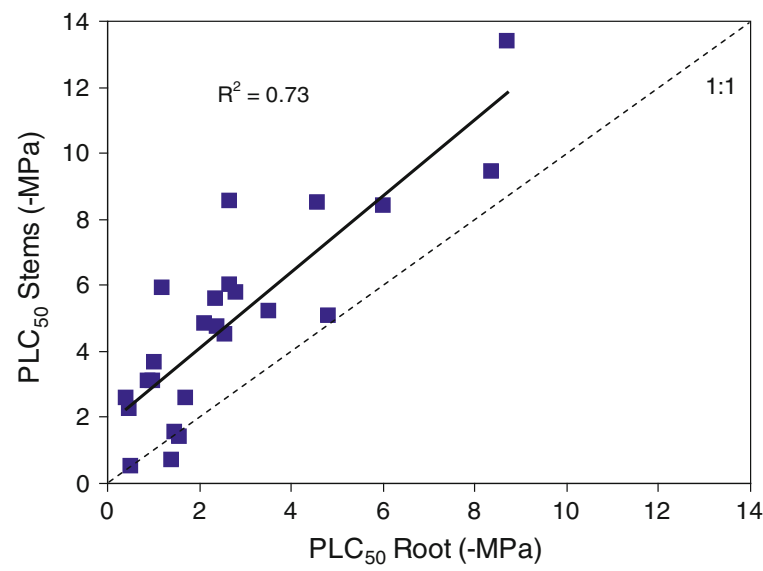

range of habitats-from mesic to xeric-in Europe. The different thresholds derived from the establishment of cavitation curves have been used for determining the distribution of plant species within (Maherali et al. 2006) and among vegetation types (Maherali et al. 2004; Bhaskar et al. 2007). Moreover, the collapse of the hydraulic conductivity of the trunk or branches has been associated with some processes of forest decline (Corcuera et al. 2006; Hoffmann et al. 2011, Peguero-Pina et al. 2011a) or with the lack of seedling recruitment in Mediterranean areas (Esteso-Martínez et al. 2006). These examples affirm the outstanding contribution of vulnerability to drought induced cavitation in woody plants in the ecology of ecosystems.

Different papers (Tyree et al. 1993; Nardini and Salleo 2000; Barigah et al. 2006) have shown that leaf hydraulic resistance constitutes the substantial component of the whole shoot or plant hydraulic. However, how much the vascular pathway contributes to this resistance should be computed before discussing the importance of leaf xylem cavitation in the SPAC dynamics. For Nardini et al. (2001), the main hydraulic restriction in the leaf lies in the non-vascular part of the pathway. The complexity of this mechanism is as high as in roots, in as far as many processes are involved (Sack et al. 2004; Sack and Holbrook 2006), including changes in aquaporin activity (Martre et al. 2002). The partitioning of the hydraulic resistance of the whole leaf $\left(\mathrm{R}_{\text {leaf }}\right)$ into the vascular resistance $\left(\mathrm{R}_{\mathrm{xylem}}\right)$ and the non-vascular resistance $\left(\mathrm{R}_{\text {outside } x y l e m}\right)$ has been a matter of study with quite controversial results. Sack and Holbrook (2006) offered a good revision of this matter, concluding that $\mathrm{R}_{\mathrm{xylem}}$ and $\mathrm{R}_{\text {outside }}$ xylem are quite similar in magnitude, although some important variation in partitioning has been found when species from different habitats have been compared.

Changes in whole leaf hydraulic resistance due to cavitation in the complex xylem network of the leaf are well documented (Sack et al. 2004), and include discussion on its importance as an ecophysiological process and explanations of biogeographic trends in leaf size (Scoffoni et al. 2011). This type of study encompasses cavitation in the petiole (e.g., Cochard et al. 2000), midrib (Nardini 
Fig. 3.10 a Vulnerability curves to drought-induced cavitation in several

European Quercus species from different habitats. In this figure, Loss of conductivity or PLC is plotted as function of water potential $(\psi)$.

Redrawn from Tognetti et al. (1998) for Q. pubescens, Tyree and Cochard (1996) for $Q$. robur and $Q$. suber, Vilagrosa et al. (2003) for $Q$. coccifera, Corcuera et al (2005) for Q. ilex subsp. ballota, Esteso-Martínez et al. (2006) for $Q$. faginea and Corcuera et al. (2006) for Q. pyrenaica. b Relationships between the length of the aridity period, i.e., the timespan during which the curve of monthly mean temperature values lies above the monthly precipitation curve in an ombro-thermic Gaussen-type graph, and the water potential at $50 \%$ loss of hydraulic conductivity $\left(\mathrm{PLC}_{50}\right)$
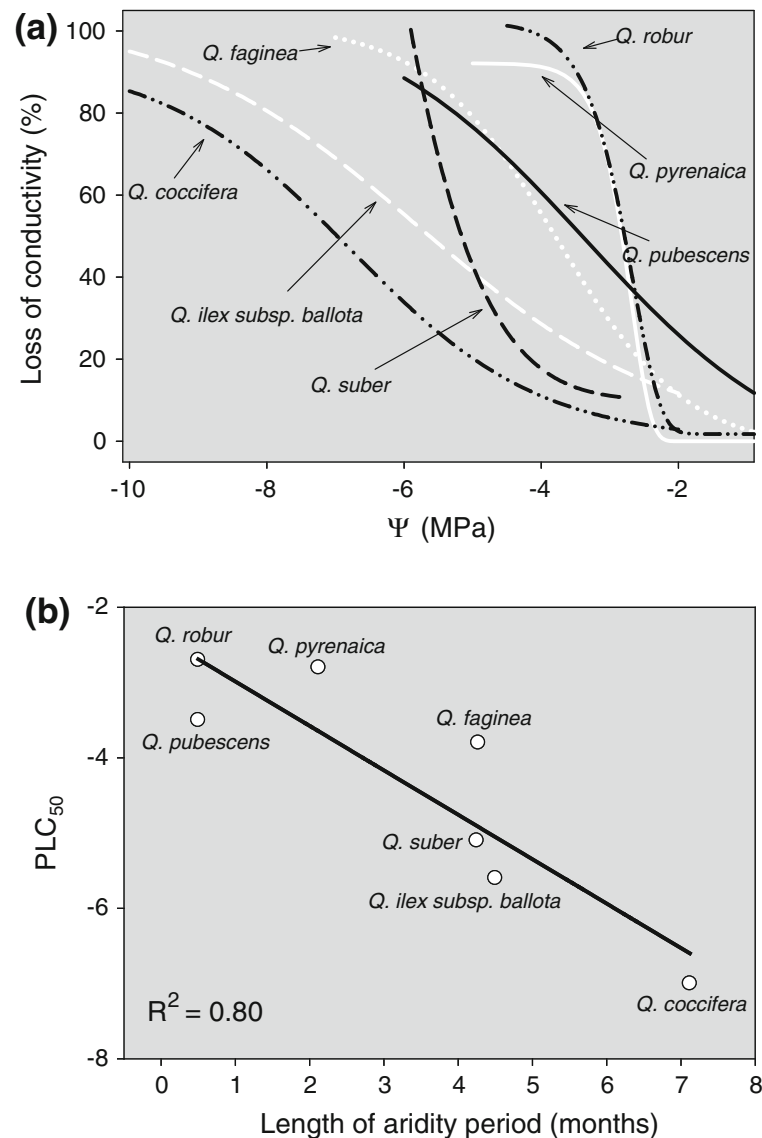

et al. 2001) and veins (Salleo et al. 2003). Nevertheless, the quantitative importance of cavitation in the vascular pathway of the whole leaf hydraulics is still under discussion (Trifilo et al. 2003). Effectively, Zufferey et al. (2011) conclude that cavitation in the petiole in grapevines can serve as a "hydraulic fuse", preserving the integrity of other organs by limiting transpiration during water stress.

\subsubsection{Other Factors Affecting Xylem Cavitation: Low Temperature and Pathogens}

Low temperatures are a major factor limiting the transport of water in the xylem (Sperry et al. 1994; Cochard et al. 2000; Feild and Brodribb 2001). The occurrence of freeze-thaw events can cause long-term effects in the hydraulic functions of the tree by inducing embolism (Mayr et al. 2006). Freezing of the conducting elements 
leads to the formation of gas bubbles, which may expand during thawing as a result of xylem tension and disrupt water transport when the bubble diameter exceeds a critical size (Davis et al. 1999; Pittermann and Sperry 2003).

The resistance of woody species to freeze-thaw embolism has been shown to rely on xylem tension, conduit diameter i.e., the larger the conduit volume, the greater quantity of gas bubbles in the sap solution, resulting in large bubbles that expand more easily during thawing than smaller bubbles (Sperry and Sullivan 1992; Sperry et al. 1994; Davis et al. 1999). This suggests that the diameter of the bubbles causing cavitation is proportional to the conduits diameter, being smaller in narrow conduits than in wider ones. A possible reason for this is that the rate of dissolving increases with bubble pressure, which is inversely proportional to bubble diameter (La Place's law; Pittermann and Sperry 2006). The degree of xylem embolism is also sensitive to the lowest temperature experienced during freezing (Pockman and Sperry 1997), although the effect of decreasing temperature may only be pronounced in some species (Pittermann and Sperry 2003). Finally, high thawing rates may also limit the rate that gas bubbles can dissolve in the surrounding water and result in the formation of embolisms (Feild and Brodribb 2001).

Species with large-diameter conduits such as ring-porous trees are almost entirely embolized at low xylem tensions after a freeze-thaw event whereas species with small-diameter conduits such as tracheid-bearing and diffuse-porous woody species, showing high resistance to freeze-thaw embolism (Sperry and Sullivan 1992; Sperry et al. 1994; Davis et al. 1999). In spite of this, the occurrence of repeated freeze-thaw events may reduce the resistance to xylem cavitation, causing embolism even in conifer species with small-diameter tracheids (Mayr et al. 2003; Mayr et al. 2006). Other factors that could cause further decreases of water potential-low soil temperatures (which limit water uptake by roots) and high radiation events during winter (which increase the loss of water by transpiration) - may induce embolism in a more vulnerable xylem due to the occurrence of repeated freeze-thaw cycles (Peguero-Pina et al. 2011a). Thus, the combined stress of low water potentials and a high number of freeze-thaw events is sufficient to induce embolism in conifers (Mayr et al. 2006).

Xylem cavitation can also be promoted by vascular diseases, which may reduce the hydraulic conductivity of the xylem by air seeding (Tyree and Sperry 1989). However, recent studies have shown that plant pathogens inhabiting the water flow under tension induce xylem cavitation through the clogging or obstruction of the xylem conduits. Thus, Martín et al. (2005) showed that the pathogenic fungi Ophiostoma novo-ulmi caused xylem vessel blocking and cavitation in Ulmus minor. In this way, McElrone et al. (2008) observed that the major effect of infection by the xylem-limited bacterial pathogen Xylella fastidiosa occurred due to reduced hydraulic conductance caused by clogging of the conduits, and not by increased cavitation of xylem elements. More recently, Raimondo et al. (2010) stated that the mitosporic fungus Phoma tracheiphila caused xylem impairment and led to leaf shedding and plant dieback in Citrus aurantium. Finally, it should be noted that the combined effect of pathogen and water stress induced reductions 
in hydraulic conductivity could promote extensive xylem dysfunction in plants subjected concurrently to both stresses (McElrone et al. 2008).

\subsubsection{Functional Implications of Xylem Cavitation: Flow Limitations to Gas Exchange, Recovery, and Refilling}

Each day, leaves of plants have to allow the evaporation of a large amount of water to uptake carbon dioxide in the stomatal cavities and also regulate their surface temperature. The machinery behind the process of water transport has to be remarkably efficient and reliable, and any dysfunction may impair tree hydration (Zwieniecki and Holbrook 1998; Salleo et al. 2000; Cochard 2006). Any drop in hydraulic conductance as a consequence of xylem cavitation leads to an impairment of many physiological processes (Nardini and Salleo 2000; Pratt et al. 2005; Jacobsen et al. 2007b). For trees, the occurrences of embolisms are commonplace as this phenomenon takes place even in well-watered plants (Milburn 1991; Brodribb and Holbrook 2004). A substantial loss of free water will result in desiccation or dehydration which increases sap tension and leads to runaway embolism (Tyree and Ewers 1991). Plants respond to drought stress by means of physiological, biochemical, and metabolic adjustments that take place throughout all plant organs (Nardini et al. 2011). For example, vascular plants in Mediterranean regions face a predictable and marked annual drought period (Jacobsen et al. 2007b) and cannot avoid water stress-induced cavitation entirely as long as they transport water under tension (Wheeler and Stroock 2008). These species should preserve xylem function if they are to maintain water transport throughout the dry and hot summer months when water shortage produces extremely negative water potentials in the xylem (Davis et al. 2002; Ackerly 2004). Not all plant species are able to withstand such negative xylem pressures and water stress-induced cavitation since embolism have been related to shoot dieback and whole-plant death (Davis et al. 2002, Martínez-Vilalta et al. 2002, Vilagrosa et al. 2003, Jacobsen et al. 2007b). According to Zwieniecki and Holbrook (1998), Domec et al. (2006) and Zufferey et al. (2011) some species can recover from their decreased hydraulic conductivity. To regain hydraulic conductivity that has been impaired by cavitation, some plants must refill their embolized conduits rapidly because of metabolic and gene expression processes which may occur within a few seconds, minutes, or hours. These processes depend on the species and genotype, the extent and severity of the water loss, the age and stage of development, the organ and cell type, and the subcellular compartment (for review, see Thapa et al. 2011). Furthermore, plant response depends on the nature of the water shortage, inducing physiological responses to short-term changes, acclimation to a certain amount of water availability and adaptation to drought (Levitt 1980; Larcher 1995).

Xylem recovery from embolism is necessary to maintain the transpiration of new leaves produced after drought resumption. Two recovery mechanisms seem to 
have evolved: building up new functional conduits and refilling of embolized ones through an active mechanism. The first mechanism is common to almost terrestrial plant species with secondary cambium for which the production of new conduits increases overall xylem functionality. Recovery from embolism is based solely on this mechanism in several tree species (Cochard et al. 2001). The second mechanism implies a refilling of air-filled conduits when the xylem water potential is near or above the atmospheric value (Tyree and Yang 1992; Tyree et al. 1999). However, recent observations indicate the occurrence of embolism removal even in the presence of negative pressures in the xylem (Holbrook and Zwieniecki 1999; Salleo et al. 2006) associated with osmosis rather than the mechanically expected potential in intact woody plants, a none-straightforward mechanism which seems to violate the laws of thermodynamics (Clearwater and Goldstein 2005; Tyree et al. 1999). Moreover, for the former authors, many of the major biophysical questions regarding refilling under tension remain unanswered.

Since understanding how embolism repair under tension occurs is critical for evaluating the costs and constraints of transporting water in a metastable state, Zwieniecki and Holbrook (2009) devoted a conceptual framework as a guideline for future studies to understand how xylem refilling under tension takes place. Recently, Brodersen et al. (2010) reported a breakthrough in xylem embolism repair under tension based on experimental observations and theoretical modeling. Using the potential of 3D high-resolution computed tomography for in vivo monitoring of embolism repair, they visualized water droplets apparently exiting from vasicentric cells and entering embolized vessels of Vitis vinifera. The droplets expand over time and refill vessels while forcing the dissolution of entrapped gases at substantially negative stem water potentials ranging between 0.45 and $-0.75 \mathrm{MPa}$ (see Nardini et al. 2011 for review). Yet, embolism repair under negative pressure continues to be an unanswered question since it is restricted to a few number of species investigated.

\subsubsection{Cavitation Plasticity: Variations Within the Tree, Populations, Ecotypes, or Cultivars}

Cavitation resistance, at the interspecific level, has been widely documented across species and varies considerably (Maherali et al. 2004; Bréda et al. 2006). Comparisons of more or less distantly related taxa growing in contrasting environments suggest that increased cavitation resistance is a key component of species growing in drought-prone habitats (Tyree and Ewers 1991; Hacke et al. 2000; Pockman and Sperry 2000). To date, Machado and Tyree (1994) report similar levels of droughtinduced cavitation in deciduous and evergreen plants, but higher levels in tropical plants than in temperate forest species. Even, reports are much scarcer at the intraspecific level, resistance to cavitation can vary significantly between populations of the same species (Alder et al. 1996; Herbette et al. 2010; Wortemann 
et al. 2011) or between closely related genotypes (Pammenter and Vander Willigen 1998; Sangsing et al. 2004; Cochard et al. 2007; Lamy et al. 2011), and between organs of the same plant (Tyree et al. 1993; Sperry and Saliendra 1994; Hacke and Sauter 1996; Cochard et al. 1999). Furthermore, Variation in resistance to drought-induced xylem cavitation has also been demonstrated among cultivars of the same species (Neufeld et al. 1992; Alsina et al. 2007).

Cochard et al. (1999) and Herbette et al. (2010) assessed the within-tree variation in vulnerability to cavitation due to light and seasonal effects. They found that light-exposed branches are less vulnerable than shaded ones. Furthermore, Lemoine et al. (2002) reported that the apical parts of beech trees experience both the lowest leaf water potential and the lowest vulnerability to cavitation. Moreover, in beech ( $F$. sylvatica L.) the number of leaf primordia preformed in the buds determines the length and the type (long versus short) of annual growth units, and thus, branch growth and architecture (Cochard et al. 2005). Actually, different plant organs have different vulnerabilities to cavitation, with roots being the most susceptible and woody stems the least susceptible (Mencuccini and Comstock 1997). Accordingly, low water potentials are most likely to cause runaway cavitation in the roots but not in the other organs. For these authors, green twigs might be adapted to the favorable water conditions of the growing season, while woody stems would be prone to endure prolonged periods of drought stress. Within an organ, wider conduits are generally more susceptible to drought-induced cavitation, but across organs or species this trend is very weak (Hacke et al. 2000). This is probably because the cavitation threshold is not determined by conduit diameter but by the pore diameter in conduit walls (Tyree and Zimmermann 2002). Moreover, a positive relationship is found between conduit wall reinforcement and stem cavitation resistance (Hacke et al. 2001). Cavitation features at leaf scale has been little investigated. Nevertheless, there is some evidence that water-stress induced reductions in leaf hydraulic conductance $\left(\mathrm{K}_{\text {leaf }}\right)$ result from leaf xylem cavitation (Nardini et al. 2001; Johnson et al. 2009). Recently, Johnson et al. (2009) measured leaf hydraulic conductance concurrently with ultrasonic acoustic emission (UAE) in the dehydrating leaves of two vessel-bearing and two tracheidbearing species to determine whether declining $\mathrm{K}_{\text {leaf }}$ was associated with an accumulation of cavitation events. In addition, they captured images of leaf internal structure with a cryo-scanning electron microscopy which enabled the detection of empty versus full as well as deformed conduits. They reported values of water potential inducing $50 \%$ loss conductivity ranging from -1.5 to $2.4 \mathrm{MPa}$ across their study species. Contrary to previous observations (Cochard et al. 2004), they did not report evidence of deformation or collapse in either Pinus nigra or Pinus ponderosa xylem tracheids (or vessels of the two angiosperm species) due to reductions in $\mathrm{K}_{\text {leaf }}$.

At the population level, Mencuccini and Comstock (1997) showed differences in vulnerability to cavitation related to differences in the environment of origin among populations of the desert shrub Ambrosia dumosa (Gray) Payne when grown in a common garden. Differences in vulnerability to cavitation among populations were evident in A. dumosa, but not in Hymenoclea salsola. Several 
studies have analyzed for variations in vulnerability to cavitation among populations in forestry species (Tognetti et al. 1998; Martínez-Vilalta et al. 2009; Herbette et al. 2010; Corcuera et al. 2011). The results of these works are contrasted and reflect a high intraspecific phenotypic plasticity. Furthermore, Corcuera et al. (2011) found a good convergence between hydraulic traits, xylem embolism, and drought tolerance of the populations. Therefore, the adjustment of hydraulic properties at leaf and shoot level can play an important role in avoiding cavitation risks (Martínez-Vilalta et al. 2009).

At the cultivar level, few studies have focused on the variability within a single species found over a broad range of environmental conditions. However, Alsina et al. 2007 compared eight 10-year-old grapevine cultivars and found large differences between them based on their sensitivity to drought-induced cavitation. Franks et al. (1995) reported that seedlings of Eucalyptus camadulensis from drier environments in Australia exhibited higher resistances to drought-induced xylem cavitation compared with seedlings from wetter environments.

\subsubsection{Coordination of Processes Between Cavitation and Cell and Leaf Function}

The vulnerability of xylem to cavitation (i.e. apoplastic resistance) is a key parameter for understanding the role of hydraulic architecture in leaf and wholeplant function. This parameter has been associated with variations in any plant functional traits that controls cell and plant functionality (Vilagrosa et al. 2010). Specifically, photosystem II (PSII) functionality, photosynthetic pigment composition, cell membrane integrity, and protein stability play an important role in cell resistance to drought stress at symplastic level. Thus, under intense drought and temperature stresses, energy dissipation mechanisms could be promoted, mediated by changes in the de-epoxidation state of the xanthophyll cycle (Morales et al. 2006) and/or photoinhibition in the photosynthetic apparatus of water-stressed leaves (Demmig-Adams and Adams 2006). Moreover, many phospholipids of biological membranes undergo phase transitions and membrane fusions that are disruptive to membrane structure and function. For these reasons, cell membranes are also considered as one of the first targets of many stresses, and maintenance of their integrity and stability under water stress conditions is a major component of drought tolerance in plants (Earnshaw 1993).

The production of a xylem with a great resistance to cavitation, which demands high investments in construction costs (Pratt et al. 2007; McCulloh et al. 2011), would be accompanied by a high tolerance at leaf level to drought conditions by means of some adaptive processes, multigene expression or regulatory networks (Valliyodan and Nguyen 2006). Thus, the functional coordination between the resistance to xylem cavitation and the response of stomatal processes has been studied by several authors, establishing the concept of "safety margin" i.e., the 
water potential at stomatal closure and the onset of cavitation events (Tyree and Sperry 1988; Meinzer et al. 2009). Wide safety margins are common in plants living in environments with severe water limitations which are able to withstand severe drought periods with leaf water potentials lower than those inducing stomatal closure but much higher than those producing the onset of cavitation events (Vilagrosa et al. 2003; Peguero-Pina et al. 2008; 2009). In this way, Vilagrosa et al. (2010) showed another safety margin between symplast resistance at leaf level and xylem cavitation which would reflect a mechanism to maintain high structural and functional stability at leaf level. Thus, the capacity to maintain costly structures (cell membranes, metabolic and photosynthetic machinery, etc.) may be an important factor for survival and competitiveness in water-limited environments.

\subsection{New Frontiers and Challenges with Xylem Cavitation as a Limiting Factor}

\subsubsection{Cavitation as the Limiting Factor for Plant Survival: Cavitation vs Starvation}

Climatic models predict a reduction in the amount of precipitation and changes in rainfall seasonality in drylands (IPCC 2010), with important effects on drought severity and duration, and/or the frequency of heat waves (Hertig and Jacobeit 2008). This phenomenon, recently referred to as "global change-type droughts" (Breshears et al. 2009), may affect species survival, distribution, and productivity (McDowell et al. 2008, van Mantgem et al. 2009; Allen et al. 2010; Zeppel et al. 2011). Plant species must adapt to new climatic conditions or become locally extinct and, in this process, natural communities may undergo substantial changes in their composition and structure (Fig. 3.11). Increasing aridity as projected by climate change models could threaten the survival of not only young pine forests, but also mature stands in some areas. In fact, this occurs right now worldwide (Allen et al. 2010; Dietze and Moorcroft 2011).

As drought affects several physiological processes at plant and cell level, numerous studies have pointed out that xylem vulnerability to drought-induced cavitation plays a key role in drought resistance (Tyree and Sperry 1989). Indeed, vulnerability to cavitation differs widely among species (Pockman and Sperry 2000), and a low vulnerability leads to a higher drought tolerance (Tyree and Ewers 1991; Maherali et al. 2004). As already pointed out, xylem cavitation as a consequence of drought stress reduces hydraulic conductivity in the root to leaf pathway, preventing plants from supplying their leaves with water (Vilagrosa et al. 2003; Bréda et al. 2006). However, this effect can be species specific since different plant functional strategies can modulate the degree of stress suffered and the extent of plant damage (Miranda et al. 2010; Pratt et al. 2010; Quero et al. 2011). 


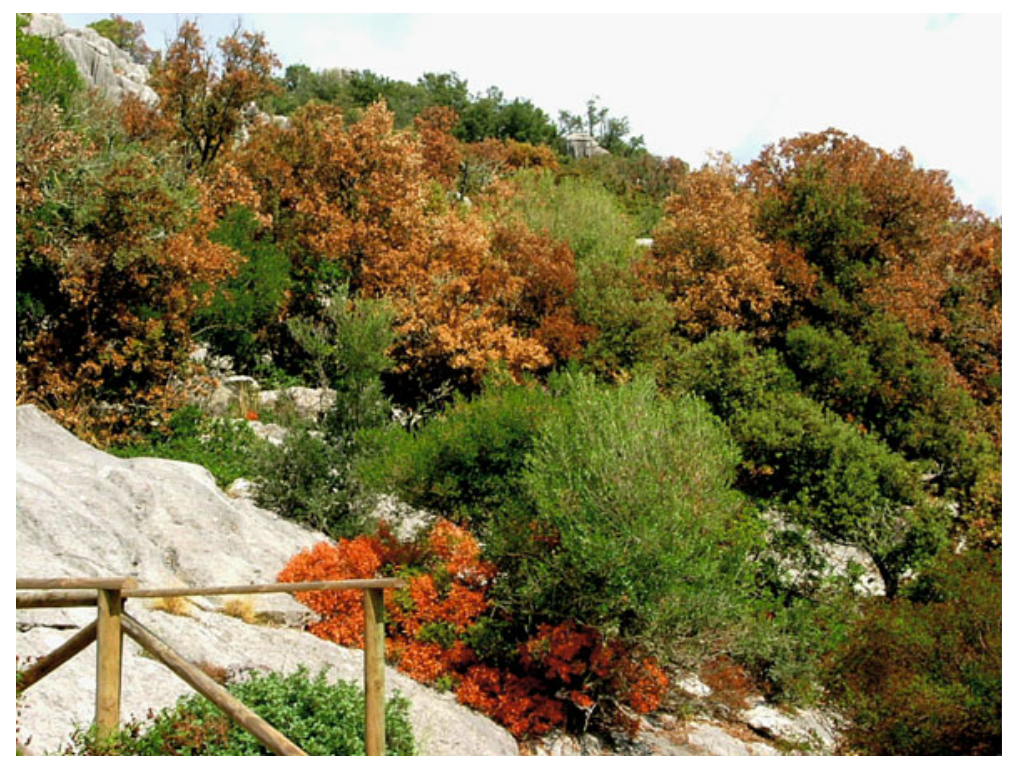

Fig. 3.11 Drought impacts on Mediterranean macchia ecosystem, Eastern of Spain in summer 2003. Several species were affected by leaf shedding during the severe drought conditions of the summer (Photograph: Vilagrosa)

In this sense, Ogaya et al. (2003) reported a differential drought effects on several coexisting species representing different functional types (shrubs and trees) in a Quercus ilex forest in Eastern Spain. Within the same ecosystem, Hernández et al. (2009); Luis et al. (2010); Pratt et al. (2010) find that inter- and intraspecies differences in root system development, rooting strategy, and xylem hydraulic traits can determine the different levels of drought stress suffered by plants, regardless of the xylem resistance to cavitation. In a study of seedling response to reforestation in a Mediterranean ecosystem (Vilagrosa 2002; Vilagrosa et al. 2003), it was observed that species most resistant to xylem cavitation (e.g., $Q$. coccifera) consistently displayed the most negative water potential for similar conditions of water availability (Fig. 3.12a), and this was consequence of the lowest root development and, therefore, the least access to soil water availability (Fig. 3.12b). In contrast, the species less resistant to cavitation, like $P$. lentiscus, developed a larger root system than Q. coccifera (Vilagrosa et al. 1997; Vilagrosa, 2002). This allowed $P$. lentiscus to get the ability to explore large and deep amount of soil and sustained hydration and less negative water potential (Fig. 3.12). In spite of its high cavitation resistance, $Q$. coccifera have always shown higher mortality rates than $P$. lentiscus within the same environmental conditions. However, Maherali et al. (2004), Pratt et al. (2010), and Meinzer et al. (2009) analyzed a wide range of functional groups and different ecosystems and pointed out that, in general, the lower the summer water potential the higher the resistance to xylem cavitation. 
Fig. 3.12 a Relationships between leaf water potential at predrawn $(\psi)$ and soil water content experienced by seedlings of $Q$. coccifera and $P$. lentiscus in the same plot. b Relationships between leaf water potential $(\psi)$ and root development measured as length of fine roots growing in the soil for the same seedlings. Circles and triangles stand for Quercus coccifera and Pistacia lentiscus, respectively. Close and open symbols represent different periods along the year, concretely three (black symbols) and 6 months (white symbols) after outplanting. All seedlings had the same age. (Redraw form Fonseca 1999)
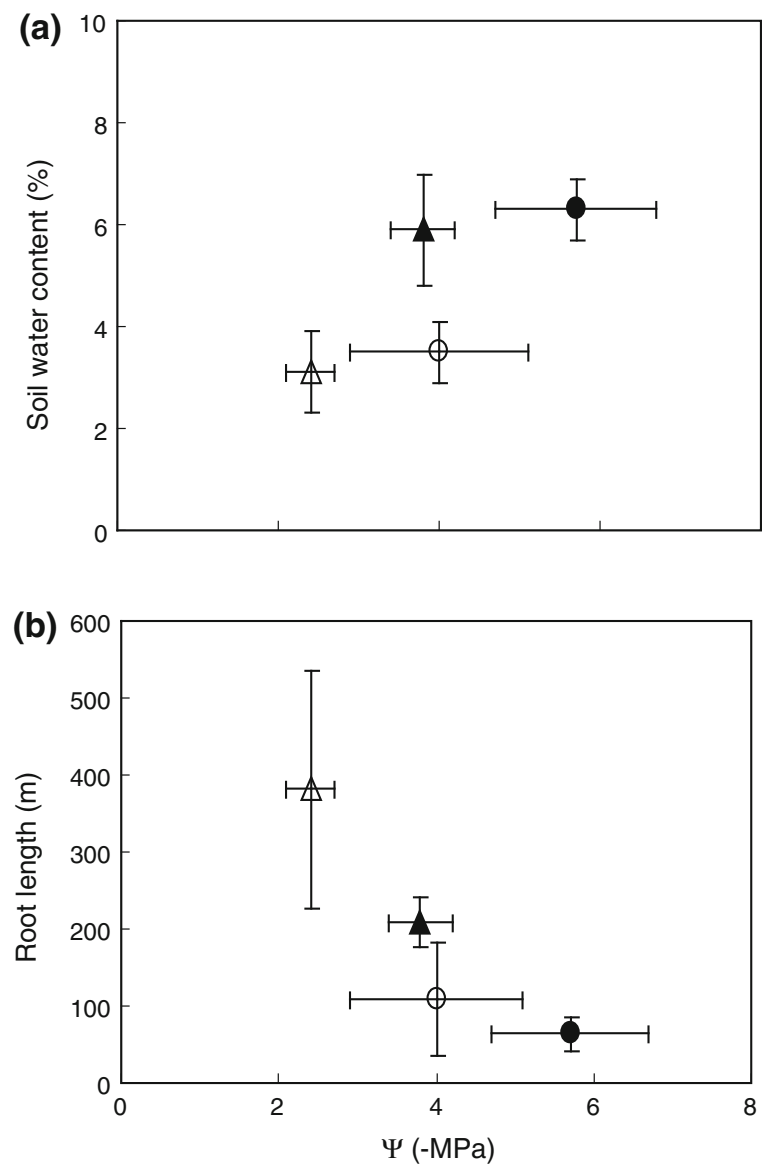

Cavitation, however, may not be the only or even the most decisive factor behind drought-induced mortality. Multiple hypotheses on the mechanisms of drought-induced mortality have been proposed. A competing hypothesis, i.e., the carbon-starvation hypothesis, has recently been forwarded (McDowell et al. 2008; Allen et al. 2010). For these authors, carbon starvation would occur in trees that regulate stomatal conductance to prevent cavitation (Fig. 3.13). This hypothesis states that mortality may be the result of decreases in $\mathrm{C}$ fixation under prolonged non-lethal drought, which would produce a debilitating effect on the trees and predispose them to indirect damages like insect or fungal attacks (McDowell et al. 2008). Thus, plants will die as consequence of starvation or diseases. Some studies in Mediterranean Spain attributed the mortality of $Q$. suber and Q. ilex trees to Phytophtora sp. attacks on trees that were previously damaged by drought (Brasier 1996). These results are in line with the observed increase in insect attacks in European forests attributable to warmer conditions (Netherer and Schopf 2010). Nevertheless, the hypothesis of starvation has been questioned due to a lack of direct evidence of low $\mathrm{C}$ in dying plants and to different patterns of carbon 


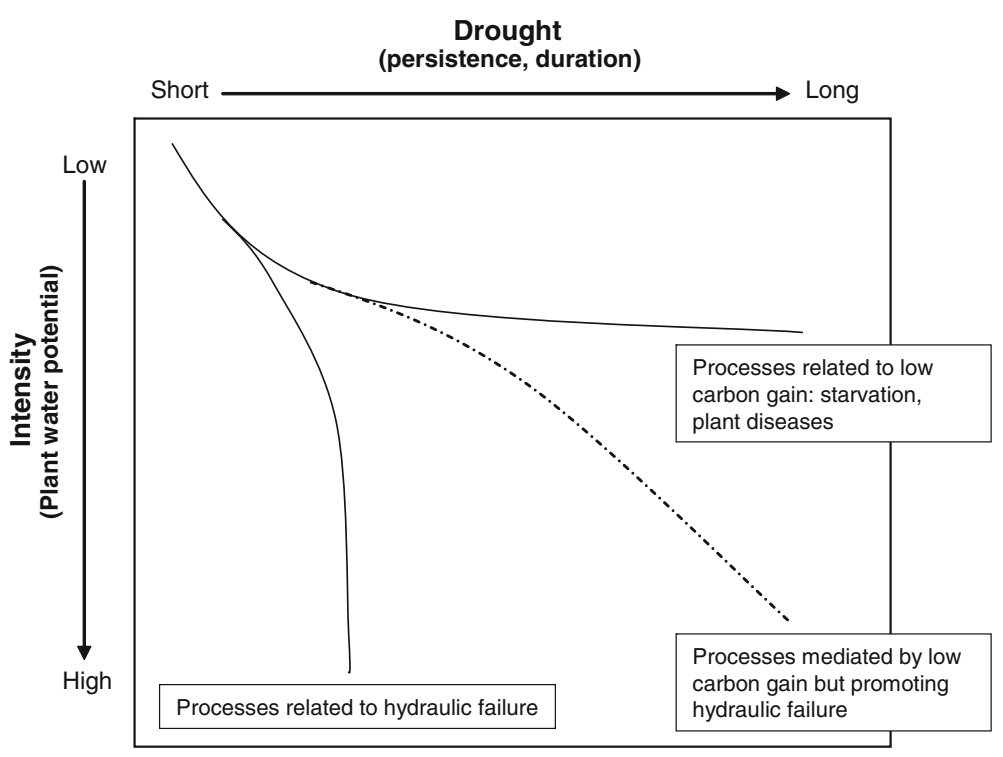

Fig. 3.13 Conceptual model relating hydraulic failure and carbon starvation as a function of drought stress duration and intensity. (From: McDowell et al. 2008 with modifications)

translocation in trees (Sala 2009; Zeppel et al. 2011; Galvez et al. 2011, but see: Galiano et al. 2011).

An intermediate pathway (Fig. 3.13, dashed line) would be the case of plants with low carbon fixation as a consequence of a high stomatal regulation which will produce a reduced capacity to growth roots and leaves. These plants would impair their ability to survive intense drought events. Therefore, lower capacity of roots to growth and colonize the soil as showed in Fig. 3.12 in Q coccifera could be an example of such intermediate pathway, with higher rates of drought stress and mortality than P. lentiscus (Vilagrosa et al. 1997 and 2003). In fact, Landhäusser and Lieffers (2012) reported that reductions in carbon fixation produced loss of roots consequence of decreases in root reserves in aspen trees. This response was related to hydraulic failures and dying of mature trees. In this context, accumulated non-structural carbohydrates can play an additional key role in determining sprouting capacity after drought (Paula and Ojeda 2009). In addition to the amount of carbon reserves, the capacity to recover and regrowth new plant structures after rewatering can be a determinant factor to survive after drought resumption. Belowground organs like those present in several Mediterranean and dryland species (such as lignotubers and burls) allow resprouter species to persist by growing new organs after disturbance (Naveh and Lieberman 1993). Vilagrosa et al. (2003) showed that Mediterranean shrubs as Q coccifera and Pistacia lentiscus were able to resprout until they reached a full hydraulic failure, i.e., $100 \%$ of the xylem conduits were embolized. These authors found that leaf shedding depends on the species and the drought severity (Fig. 3.14). When drought was severe, plants 


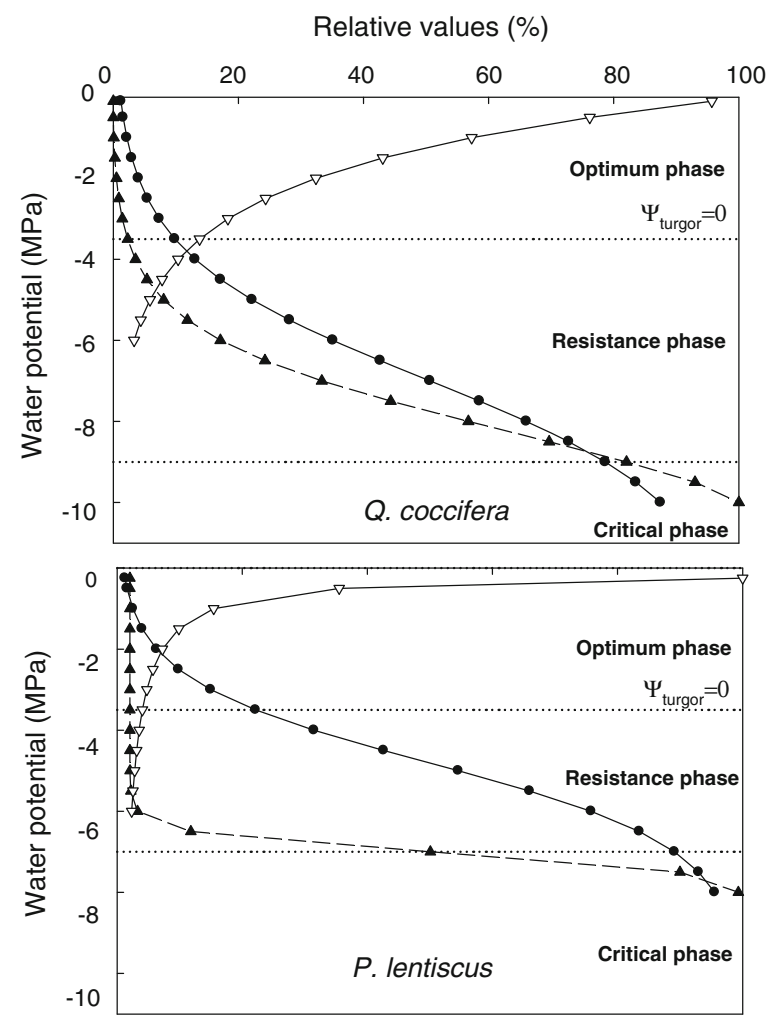

Fig. 3.14 Curves showing three different phases during an extreme drought stress period in two drought resistant Mediterranean shrubs: Quercus coccifera and Pistacia lentiscus. We identified three phases before plant death: the optimum phase coincided with positive turgor which produced only a stomatal regulation to avoid dehydration. No damages were observed. After this phase, the resistance phase corresponded to the first damages which lead to a few losses of leaves and a moderate loss of conductivity. All the plants recovered after irrigation. The critical phase corresponded to the extreme stress conditions, i.e., loss of conductivity higher than $80 \%$, which produced a noteworthy leaf shedding with important mortality for target plants. However, some plants were able to resprout from the base of their stems after rewatering. Other plants died probably because they experienced almost a complete loss of conductivity (i.e., $100 \%$ xylem cavitation) (From Vilagrosa 2002; Vilagrosa et al. 2003 and 2010). Open and close triangles and close circles stand for stomatal conductance, leaf shedding, and xylem cavitation, respectively. To facilitate comparisons between species, the units are expressed as a percentage of their maximum values

should need to rebuild the entire canopy (branches and leaves), while in other cases, only new leaves need to be grown. Vulnerability to drought should affect the investment needed to recover after drought episode, i.e., the amount of carbon needed to rebuild the canopy. Thus, a plant's ability to preserve functional meristems under drought should substantially affect its capacity to withstand intense and recurrent droughts (Vilagrosa et al. 2003; Brodribb and Cochard 2009; Vilagrosa et al. 2010; Hoffmann et al. 2011). 


\subsubsection{Combination of Factors Affecting Xylem Cavitation in the Context of Global Warming: Summer Drought or Winter Frost?}

In Mediterranean areas, summer drought and winter cold are the main factors limiting plant growth (Mitrakos 1980). The existence of two potential stress periods must be considered when explaining the ecological functioning of Mediterranean vegetation (Corcuera et al. 2005). On the one hand, substantial negative water potentials can be found in plants experiencing periods of intense summer drought, which can drive the xylem tension high enough to induce water stressmediated xylem cavitation. On the other hand, winter cold is prone to limits the transport of water in the xylem and the occurrence of freeze-thaw events can cause long-term effects on the hydraulic functions of the tree because of embolism.

The survival of plant species in climates with water limitations should be related to the resistance of their xylem to cavitation (Pockman and Sperry 2000; Maherali et al. 2004). Martínez-Vilalta et al. (2009) detected an adjustment between hydraulic traits and environmental conditions, resulting in greater hydraulic capacity on dry sites. However, the same study underlies the fact that vulnerability to drought-induced cavitation was unrelated to climate dryness. For Addington et al. (2006) a greater hydraulic sufficiency of stems to supply water to leaves may be required to prevent excessive diurnal and seasonal declines in leaf water potential under high evaporative demand. Besides, Bhaskar et al. (2007) compared pairs of species and they found that a shift in hydraulic traits was a common response in species from Mediterranean-type climates. This shift seemed to be a strategy to cope with the high evaporative demand caused by atmospheric dryness.

One way to improve the xylem hydraulic capacity is to increase xylem conduit diameters, which would decrease xylem hydraulic resistivity (Pittermann et al. 2006). However, this functional advantage may be a risky solution. Different studies have shown that the large early-wood vessels of ring-porous trees, which are responsible for the majority of the water flow in this kind of xylem (Corcuera et al. 2004), are more vulnerable to cavitation than small vessels (Cochard and Tyree 1990; Corcuera et al. 2006). Recently, this fact has been mechanistically explained by the "rare pit" hypothesis (Christman et al. 2012). This hypothesis predicts that vessels with a large area of inter-vessel pits have a greater chance of presenting a pit with relatively low air-seeding pressure, reducing the threshold pressure for cavitation of the whole conduit (Christman et al. 2009). These mechanisms could also explain the accumulation of evidences that seems to indicate that the larger the conduit the more vulnerable to water stress induced cavitation when the comparison is done among species (Wheeler et al. 2005; Hacke et al. 2006).

Another risk associated to the formation of wide conduits is the well-known increased vulnerability to freezing-thawing induced cavitation during winter that species with large-diameter conduits can experience (Cochard and Tyree 1990; 
Sperry and Sullivan 1992; Mayr and Sperry 2010). Therefore, a new ecological tradeoff arises, i.e., an improved hydraulic efficiency-which would help to cope with summer drought - could prevent the plant from occupying areas where the temperatures decrease below zero during winter.

Recently, Peguero-Pina et al. (2011b) studied this tradeoff by comparing under different environmental conditions the hydraulic traits of Abies alba and A. pinsapo, two closely related fir species occurring in the Iberian Peninsula. In fact, $A$. alba proliferates in humid European mountains (including the Spanish Pyrenees) while A. pinsapo, a relict species, grows only in a few restricted areas of Mediterranean mountains in Spain and Morocco, where intense summer drought periods are commonplace. Although both species does not differ in the resistance to cavitation, these authors find that $A$. pinsapo shows a higher efficiency of water transport in terms of specific and leaf hydraulic conductance. These results should contribute to maintaining its xylem tension below the threshold for rapidly increasing cavitation. Thus, the improvement of xylem sufficiency for supplying water to the transpiring needles in A. pinsapo can be considered a necessary and sufficient condition for coping with the high atmospheric evaporative demand, a characteristic of the Mediterranean summer. For Mayr and Sperry (2010), it is noteworthy that the higher $K_{\mathrm{s}}$ in $A$. pinsapo is largely a result of its wider tracheids, suggesting that this species may be much more vulnerable to freeze-thaw induced cavitation than $A$. alba. Nowadays, the expansion of $A$. pinsapo in the Iberian Peninsula toward Northern sites occupied by $A$. alba can be limited by the great occurrence of freeze-thaw events in these areas. However, the predicted increase in temperature and aridity due to global climate change (Barnett et al. 2005) can allow the geographic displacement of $A$. pinsapo in latitude and/or altitude.

\subsection{Concluding Remarks}

During last decades, plant hydraulic architecture and xylem cavitation have evolved as one of the major trends in plant water-relations studies. However, our understanding of the plant hydraulic architecture is far from being completely understood. Particularly, the two ends of the plant hydraulic pathway i.e., roots and leaves, remain poorly studied even new advances are currently in progress. In addition, aquaporins and their relative contribution to water flow within apoplastic, symplastic, and transmembrane pathways are not well characterized yet mainly in leaves and roots.

Hydraulic efficiency and vulnerability to cavitation determine many aspects of plant functioning. Several studies have reported that adaptation of hydraulic characteristics is integrally linked to ecosystem properties as light, nutrients, or water. A breakthrough in this area would allow us to predict plant responses at individual and community level in the context of changing environmental conditions. In this sense, there are currently uncertainties about climate-induced plant mortality and particularly, the mechanisms that drive forests dieback worldwide as well as the physiological thresholds priming the tree death. Research with large 
databases on functional features including those relating plant hydraulics and vulnerability to cavitation will allow an integrated analysis providing common response patterns that can assist to ecosystem management.

Plant functional traits and biochemical processes involved in water transport, gas exchange regulation, and plant damage or cell death are clearly noteworthy to relationships between species and adaptation to the environment, especially in the light of the new perspectives on climate projections. Although the mechanisms of xylem cavitation are relatively well established, there is still a need for settling and sharing a common protocol to improve our ability to compare species and biomes for their functional traits and drought-resistance strategies. The relative importance of root and/or stem xylem cavitation and their relative contribution to whole plant water flow and their capacity for recovery after drought should be taken into consideration when analyzing physiological activity and plant response to drought episodes. Furthermore, the role of genomics in the control and expression of genes involved in the regulations and mechanisms affecting the water transport system may deserve much more attention. In addition, the analysis of combinations of stress factors i.e., drought, freezing-thawing and their influence on xylem cavitation, and plant hydraulics should improve the capacity to integrate different processes in overall plant and ecosystem functioning.

Acknowledgements This chapter reviews and summarizes some of the outputs generated from research projects funded by the European Commission (CREOAK project QLRT-2001-01594; FUME Grant Agreement $n^{\circ}$ 243888), the Spanish Ministry of Science and Innovation (PERSIST CGL2006-07126; GRACCIE-CSD2007-00067 CONSOLIDER-INGENIO Program; SUMIDEROS SUM2008-00004-C03-03; CASISFOR AGL2010-21153-C02-02; SURVIVE CGL2011-30531C02-02) and the Spanish Ministry of the Environment (ESTRES 063/SGTB/2007/7.1), as well as by the Regional Government of Valencia (XYLREFOR GRUPOS 03/155; APLITEC GV 05/208; INNOVA GVPRE/2008/085; FEEDBACKS-PROMETEO/2009/006).

We greatly thank the Regional Forest Service (Consellería de Infraestructures, Territori i Medi Ambient, Regional Government of Valencia) for funding our research goals. We also sincerely thank Jacqueline Scheiding for the English proofreading of the text and two anonymous reviewers who provided excellent feedback for the manuscript improvement. Fundación CEAM is supported by Generalitat Valenciana.

\section{References}

Ackerly DD (2004) Functional strategies of chaparral shrubs in relation to seasonal water deficit and disturbance. Ecol Monogr 74:25-44

Addington RN, Donovan LA, Mitchell RJ, Vose JM, Pecot SD, Jack SB, Hacke UG, Sperry JS, Oren R (2006) Adjustments in hydraulic architecture of Pinus palustris maintain similar stomatal conductances in xeric and mesic habitats. Plant Cell Environ 29:535-545

Alder NN, Sperry JS, Pockman WT (1996) Root and stem xylem embolism, stomatal conductance and leaf turgor in Acer grandidentatum populations along a soil moisture gradient. Oecologia 105:293-301

Allen CD, Macalady AK, Chenchouni H, Bachelet D, Mcdowell N, Vennetier M, Kitzberger T, Rigling A, Breshears DD, Hogg EH, Gonzalez P, Fensham R, Zhang Z, Castro J, Demidova 
N, Lim JH, Allard G, Running SW, Semerci A, Cobb N (2010) A global overview of drought and heat-induced tree mortality reveals emerging climate change risks for forests. Forest Ecol Manag 259:660-684

Alsina MM, De Herralde F, Aranda X, Save R. Biel C (2007) Water relations and vulnerability to embolism are not related: experiments with eight grapevine cultivars. Vitis 46:1-6

Andersen CP, Bussler BH, Chaney WR, Pope PE, Byrnes WR (1989) Concurrent establishment of ground cover and hardwood trees on reclaimed mined land and un mined reference sites. Forest Ecol Manag 28:81-99

Angeles G, Bond B, Boyer JS, Brodribb T, Brooks JR, Burns MJ, Cavender-Bares J, Clearwater M, Cochard H, Comstock J, Davis SD, Domec J-C, Donovan L, Ewers F, Gartner B, Hacke U, Hinckley T, Holbrook NM, Jones HG, Kavanagh K, Law B, López-Portillo J, Lovisolo C, Martin T, Martínez-Vilalta J, Mayr S, Meinzer FC, Melcher P, Mencuccini M, Mulkey S, Nardini A, Neufeld HS, Passioura J, Pockman WT, Pratt RB, Rambal S, Richter H, Sack L, Salleo S, Schubert A, Schulte P, Sparks JP, Sperry J, Teskey R, Tyree M (2004) The cohesion-tension theory. New Phytol 163:451-452

Barigah TS, Ibrahim T, Bogard A, Faivre-Vuillin B, Lagneau LA, Montpied P, Dreyer E (2006) Irradiance-induced plasticity in the hydraulic properties of saplings of different temperate broad-leaved forest tree species. Tree Physiol 26:1505-1516

Barnett TP, Adam JC, Lettenmaier DP (2005) Potential impacts of a warming climate on water availability in snow-dominated regions. Nature 438:303-309

Bhaskar R, Valiente-Banuet A, Ackerly DD (2007) Evolution of hydraulic traits in closely related species pairs from mediterranean and nonmediterranean environments of North America. New Phytol 176:718-726

Black CR (1979). The relationship between transpiration rate, water potential, and resistances to water movement in sunflower (Helianthus annuus L). J Exp Bot 30:235-243

Böhm J (1893) Capillarität und Saftsteigen. Ber Dtsch Bot Ges 11:203-212

Boyer JS (1985) Water transport. Ann Rev Plant Physiol 36:473-516

Brasier CM (1996) Phytophthora cinnamomi and oak decline in southern Europe. Environmental constraints including climate change. Ann Sci For 53:347-358

Bréda N, Huc R, Granier A, Dreyer E (2006) Temperate forest trees and stands under severe drought: a review of ecophysiological responses, adaptation processes and long-term consequences. Ann For Sci 63:625-644

Breshears DD, Myers OB, Meyer CW, Barnes FJ, Zou CB, Allen CD, Mcdowell NG, Pockman WT (2009) Tree die-off in response to global change-type drought: mortality insights from a decade of plant water potential measurements. Front Ecol Environ 7:185-189

Brodersen CR, McElrone AJ, Choat B, Matthews MA, Shackel KA (2010) The dynamics of embolism repair in xylem: in vivo visualizations using high-resolution computed tomography. Plant Physiol 154:1088-1095

Brodribb TJ, Cochard H (2009) Hydraulic failure defines the recovery and point of death in water-stressed conifers. Plant Physiol 149:575-584

Brodribb TJ, Holbrook NM (2003) Stomatal closure during leaf dehydration, correlation with other leaf physiological traits. Plant Physiol 132:2166-2173

Brodribb TJ, Holbrook NM (2004) Stomatal protection against hydraulic failure: a comparison of coexisting ferns and angiosperms. New Phytol 162:663-670

Bucci SJ, Scholz FG, Goldstein G, Meinzer FC, Franco AC, Campanello PI, Villalobos-Vega R, Bustamante M, Miralles-Wilhelm F (2006) Nutrient availability constrains the hydraulic architecture and water relations of savannah trees. Plant Cell Environ 29:2153-2167

Canny MJ (1995a) Potassium cycling in Helianthus: ions of the xylem sap and secondary vessel formation. Phil Trans R Soc Lond B 348:457-469

Canny MJ (2001) Contributions to the debate on water transport. Am J Bot 88:43-46

Chapin FS (1991) Effects of multiple stresses on nutrient availability and use. In: Mooney HA, Winner WE, Pell EJ, Chu E (eds), Response of plants to multiple stresses. Academic Press, San Diego, pp 67-88 
Chirino E, Vilagrosa A, Cortina J, Valdecantos A, Fuentes D, Trubat R, Luis VC, Puértolas J, Bautista S, Baeza J, Penuelas JL, Vallejo VR (2009) Ecological restoration in degraded drylands: the need to improve the seedling quality and site conditions in the field. In: Grossberg SP (ed), Forest management, Nova Science Publishers, Inc., New York, pp 85-158

Chirino E, Vilagrosa A, Hernández EI, Matos A, Vallejo VR (2008) Effects of a deep container on morpho-functional characteristics and root colonization in Quercus suber L. seedlings for reforestation in mediterrranean climate. Forest Ecol Manag 256:779-785

Choat B, Drayton WM, Brodersen C, Matthews MA, Shackel KA, Wada H, McElrone AJ (2010) Measurement of vulnerability to water stress-induced cavitation in grapevine: a comparison of four techniques applied to a long-vesseled species. Plant Cell Environ 33:1502-1512

Christman MA, Sperry JS, Adler FR (2009) Testing the 'rare pit' hypothesis for xylem cavitation resistance in three species of Acer. New Phytol 182:664-674

Christman MA, Sperry JS, Smith DD (2012) Rare pits, large vessels, and extreme vulnerability to cavitation in a ring-porous tree species. New Phytol 193:713-720

Clearwater MJ, Goldstein G (2005) Embolism repair and long distance water transport. In: Holbrook NM, Zwieneicki MA. (eds) Vascular transport in plants, Elsevier Academic Press, Burlington, pp 375-400

Cochard H (2006) Cavitation in trees. C R Physique 7:1018-1026

Cochard H, Bodet C, Ameglio T, Cruiziat P (2000). Cryo-scanning electron microscopy observations of vessel content during transpiration in walnut petioles. Facts or artifacts? Plant Physiol 124:1191-1202

Cochard H, Cruiziat P, Tyree MT (1992) Use of positive pressures to establish vulnerability curves: further support for the air-seeding hypothesis and implications for pressure-volume analysis. Plant Physiol 100:205-209

Cochard H, Damour G, Bodet C, Tharwat I, Poirier M, Ameglio T (2005) Evaluation of a new centrifuge technique for rapid generation of xylem vulnerability curves. Physiol Plant 124:410-418

Cochard H, Forestier S, Améglio T (2001) A new validation of the Scholander pressure chamber technique based on stem diameter variations. J Exp Bot 52:1361-1365

Cochard H, Froux F. Mayr S, Coutand C (2004) Xylem wall collapse in water-stressed pine needles. Plant Physiol 134:401-408

Cochard H, Herbette S, Barigah T, Badel E, Ennajeh M, Vilagrosa A (2010) Does sample length influence the shape of xylem embolism vulnerability curves? A test with the cavitron spinning technique. Plant Cell Environ 33:1543-1552

Cochard H, Herbette S, Hernandez E, Hölttä T, Mencuccini M (2010) The effects of sap ionic composition on xylem vulnerability to cavitation. J Exp Bot 61:275-285

Cochard H, Lemoine D, Dreyer E (1999) The effects of acclimation to sunlight on the xylem vulnerability to embolism in Fagus sylvatica L. Plant Cell Environ 22:101-108

Cochard H, Martin R, Gross P, Bogeat-Triboulot MB (2000a) Temperature effects on hydraulic conductance and water relations of Quercus robur L. J Exp Bot 51:1255-1259

Cochard H, Bodet C, Ameglio T, Cruiziat P (2000b) Cryo-scanning electron microscopy observations of vessel content during transpiration in walnut petioles. Facts or artifacts? Plant Physiol 124:1191-1202

Cochard H, Venisse JS, Barigah TS, Brunel N, Herbette S, Guilliot A, Tyree MT, Sakr S (2007) Putative role of aquaporins in variable hydraulic conductance of leaves in response to light. Plant Physiol 143:122-130

Cochard H. (2006) Cavitation in trees. C R Phys 7:1018-1026

Cochard H, Holtta T, Herbette S, Delzon S, Mencuccini M (2009) New insights into the mechanisms of water-stress-induced cavitation in conifers. Plant Physiol 151:949-954

Corcuera L, Camarero JJ, Gil-Pelegrín E (2004) Effects of a severe drought on growth and wood anatomical properties of Quercus faginea. IAWA Jour 25:185-204

Corcuera L, Camarero JJ, Sisó S, Gil-Pelegrin E (2006) Radial-growth and wood-anatomical changes in overaged Quercus pyrenaica coppice stands: functional responses in a new Mediterranean landscape 20:91-98 
Corcuera L, Cochard H, Gil-Pelegrin E, Notivol E (2011) Phenotypic plasticity in mesic populations of Pinus pinaster improves resistance to xylem embolism (P50) under severe drought. Trees-Struct Funct 25:1033-1042

Corcuera L, Morales F, Abadia A, Gil-Pelegrin E (2005) Seasonal changes in photosynthesis and photoprotection in a Quercus ilex subsp ballota woodland located in its upper altitudinal extreme in the Iberian Peninsula. Tree Physiol 25:599-608

Crombie D S, Hipkins M F, Milburn A (1985) Gas penetration of pit membranes in the xylem of rhododendron as the cause of acoustically detectable sap cavitation. Aust J Plant Physiol $12: 445-53$

Davis SD, Ewers FW, Sperry JS, Portwood KA, Crocker MC, Adams GC (2002) Shoot dieback during prolonged drought in Ceanothus chaparral of California: a possible cause of hydraulic failure. Am J Bot 89:820-828

Davis SD, Sperry JS, Hacke UG (1999) The relationship between xylem conduit diameter and cavitation caused by freezing. Am J Bot 86:1367-1372

Delzon S, Douthe C, Sala A, Cochard H (2010) Mechanism of water-stress induced cavitation in conifers: bordered pit structure and function support the hypothesis of seal capillary-seeding. Plant Cell Environ 33:2101-2111

Demmig-Adams B, Adams III WW (2006) Photoprotection in an ecological context: the remarkable complexity of thermal energy dissipation. New Phytol 172:11-21

Dietze M, Moorcroft PR (2011) Tree mortality in the eastern and central United States: patterns and drivers. Glob Change Biol 17:3312-3326

Dixon HH, Joly J (1895) On the ascent of sap. Philos Trans R Soc Lond 186:563-576

Domec J-C, Scholz FG, Meinzer FC, Goldstein G, Villalobos-Vega R (2006) Diurnal and seasonal variation in root xylem embolism in neotropical savanna woody species: impact on stomatal control of plant water status. Plant Cell Environ 29:26-35

van Doorn WG, Hiemstra T, Fanourakis D (2011) Hydrogel regulation of xylem water flow: an alternative hypothesis. Plant Physiol 157:1642-1649

Earnshaw MJ (1993) Stress indicators: electrolyte leakage. In: Hendry GAF, Grime JP (eds) Methods in comparative plant ecology. Chapman and Hall, London, pp 152-154

Esteso-Martinez J, Camarero JJ, Gil-Pelegrin E (2006) Competitive effects of herbs on Quercus faginea seedlings inferred from vulnerability curves and spatial-pattern analyses in a Mediterranean stand (Iberian System, northeast Spain). Ecoscience 13:378-387

Ewers B, Oren R, Sperry J (2000) Influence of nutrient versus water supply on hydraulic architecture and water balance in Pinus taeda. Plant Cell Environ 23:1055-1066

Feild TS, Brodribb T (2001) Stem water transport and freeze-thaw xylem embolism in conifers and angiosperms in a Tasmanian treeline heath. Oecologia 127:314-320

Fonseca DE (1999) Manipulaciones de las características morfoestructurales de plantonesde especies forestales mediterráneas producidas en vivero. Zaragoza M.Sc Thesis. CIHEAMIAMZ, Zaragoza

Franks PJ, Gibson A, Bachelard EP (1995) Xylem permeability and embolism susceptibility in seedlings of Eucalyptus camaldulensis Dehnh from two different climatic zones. Aust J Plant Physiol 22:15-21

Frensch J, Steudle E (1989) Axial and radial hydraulic resistance to roots of maize (Zea mays L). Plant Physiol 91:719-726

Froux F, Ducrey M, Dreyer E, Huc R (2005) Vulnerability to embolism differs in roots and shoots and among three mediterranean conifers: consequences for stomatal regulation of water loss? Trees-Struct Funct 19:137-144

Galiano L, Martínez-Vilalta J, Lloret F (2011) Carbon reserves and canopy defoliation determine the recovery of Scots pine 4 yr after a drought episode. New Phytol 190:750-759

Galvez DA, Landhäusser SM, Tyree MT (2011) Root carbon reserve dynamics in aspen seedlings: does simulated drought induce reserve limitation? Tree Physiol 31:250-257

Hacke U, Sauter JJ (1996) Drought-induced xylem dysfunction in petioles, branches and roots of Populus balsamifera L. and Alnus glutinosa (L) Gaertn. Plant Physiol 111:413-417 
Hacke UG, Sperry JS, Pittermann J (2000) Drought experience and cavitation resistance in six shrubs from the great basin, Utah. Basic Appl Ecol 1:31-41

Hacke UG, Sperry JS, Pockman WT, Davis SD, McCulloh KA (2001) Trends in wood density and structure are linked to prevention of xylem implosion by negative pressure. Oecologia 126:457-461

Hacke UG, Sperry JS, Wheeler JK, Castro L (2006) Scaling of angiosperm xylem structure with safety and efficiency. Tree Physiol 26:689-701

Hafren J, Daniel G, Westermark U (2000) The distribution of acidic and esterified pectin in cambium, developing xylem and mature xylem of Pinus sylvestris. IAWA J 21:157-168

Hao GY, Hoffmann WA, Scholz FG, Bucci SJ, Meinzer FC, Franco AC, Cao KF Goldstein G (2008) Stem and leaf hydraulics of congeneric tree species from adjacent tropical savanna and forest ecosystems. Oecologia 155:405-415

Harvey HP, Van den Driessche R (1997) Nutrition, xylem cavitation and drought resistance in hybrid poplar. Tree Physiol 17:647-654

Herbette S, Wortemann R, Awad H, Huc R, Cochard H, Barigah TS (2010) Insights into xylem vulnerability to cavitation in Fagus sylvatica L: phenotypic and environmental sources of variability. Tree Physiol 30:1448-1455

Herbette S. Cochard H (2010) Calcium is a major determinant of xylem vulnerability to cavitation. Plant Physiol 153:1932-1939

Hernández EI, Pausas JG, Vilagrosa A (2011) Leaf physiological traits in relation to resprouter ability in the Mediterranean Basin. Plant Ecol 212:1959-1966

Hernández EI, Vilagrosa A, Luis VC, Llorca M, Chirino E, Vallejo VR (2009) Root hydraulic conductance, gas exchange and leaf water potential in seedlings of Pistacia lentiscus $\mathrm{L}$ and Quercus suber $\mathrm{L}$ grown under different conditions of fertilization and light regimes. Environ Exp Bot 67:269-276

Hernández EI, Vilagrosa A, Pausas JG, Bellot J (2010) Morphological traits and water use strategies in seedlings of Mediterranean coexisting species. Plant Ecol 207:233-244

Hertig E, Jacobeit J (2008) Downscaling future climate change: temperature scenarios for the Mediterranean area. Global Planet Change 63:127-131

Hoffmann WA, Marchin RM, Abit P, Lau OL (2011) Hydraulic failure and tree dieback are associated with high wood density in a temperate forest under extreme drought. Glob Change Biol 17:2731-2742

Holbrook NM, Zwieniecki MA (1999) Embolism repair and xylem tension. Do we need a miracle? Plant Physiol 120:7-10

Holbrook NM, Zwieniecki MA (2005) Vascular trasnport in plants. Elsevier Academic Press, USA

Hölttä T, Cochard H, Nikinmaa E, Mencuccini M (2009) Capacitive effect of cavitation in xylem conduits: results from a dynamic model. Plant Cell Environ 32:10-21

Huang B, Nobel PS (1993) Hydraulic condctivity and anatomy along lateral roots of cactichanges with soil water status. New Phytol 123:449-507

Hubbard RM, Ryan MG, Stiller V, Sperry JS (2001) Stomatal conductance and photosynthesis vary linearly with plant hydraulic conductance in ponderosa pine. Plant Cell Environ 24:113-121

Huber B (1928) Weitere quantitative Untersuchungen über das Wasserleitungs system der Pflanzen. Jahrb Wiss Bot 67:877-959

Hukin D, Cochard H, Dreyer E, Le Thiec D, Bogeat-Triboulot MB (2005) Cavitation vulnerability in roots and shoots: does Populus euphratica Oliv., a popular from arid areas of Central Asia, differ from other poplar species?. J Exp Bot 53:2003-2010

IPCC (2010) Meeting report of the intergornmental panel on climate change, expert meeting on detection and attribution related to anthropogenic climate change. IPCC Working Group I Technical support unit, university of Bern, Switzerland, pp 55

Jackson GE, Grace J (1996) Field measurements of xylem cavitation: are acoustic emissions useful? J Exp Bot 47:1643-1650

Jackson RB, Sperry JS, Dawson TE (2000) Root water uptake and transport: using physiological processes in global predictions. Trends Plant Sci 5:482-488 
Jacobsen AL, Agenbag L, Esler KJ, Pratt RB, Ewers FW, Davis SD. 2007a. Xylem density, biomechanics, and anatomical traits correlate with water stress in seventeen evergreen shrub species of the Mediterranean-type climate region of South Africa. J Ecol 95:171-183

Jacobsen AL, Pratt RB, Davis SD, Ewers FW (2008) Comparative community physiology: nonconvergence in water relations among three semi-arid shrub communities. New Phytol 180:100-113

Jacobsen AL, Pratt RB, Ewers F, Davis SD (2007) Cavitation resistance among 26 chaparral species of southern California. Ecol Monogr 77:99-115

Jansen S, Gortan E, Lens F, Lo Gullo MA, Salleo S, Scholz A, Stein A, Trifilò P, Nardini A (2011) Do quantitative vessel and pit characters account for ion-mediated changes in the hydraulic conductance of angiosperm xylem? New Phytol 189:218-228

Jarbeau JA, Ewers FW, Davis SD (1995) The mechanism of water-stress-induced embolism in two species of chaparral shrubs. Plant Cell Environ 18:189-196

Javot H, Maurel C (2002) The role of aquaporins in root water uptake. Ann Bot 90:301-13

Johnson DM, Woodruff, DR McCulloh KA, Meinzer FC (2009) Leaf hydraulic conductance, measured in situ, declines and recovers daily: leaf hydraulics, water potential and stomatal conductance in four temperate and three tropical tree species. Tree Physiol 29:879-887

Jones HG (1992) Plants and Microclimate. A quantitative approach to environmental plant physiology. Cambridge University Press, Cambridge

Kaldenhoff R, Ribas-Carbó M, Flexas-Sans J, Lovisolo C, Heckwolf M, Uehlein N (2008) Aquaporins and plant water balance Plant Cell Environ 31:658-666

Kikuta SB, Hietz P, Richter H (2003) Vulnerability curves from conifer sapwood sections exposed over solutions with known water potentials. J Exp Bot 54:2149-2155

Koch GW, Sillett SC, Jennings GM, Davis SD (2004) The limits to tree height. Nature 428: $851-854$

Kolb KJ, Sperry JS, Lamont BB. (1996) A method for measuring xylem hydraulic conductance and embolism in entire root and shoot systems. J Exp Bot 47:1805-1810

Kozlowski T T, Kramer P J, Pallardy S G (1991) The physiological ecology of woody plants. Academic Press, Toronto

Lamy JB, Bouffier L, Burlett R, Plomion C, Cochard H, Delzon S (2011) Uniform selection as a primary force reducing population genetic differentiation of cavitation resistance across a species range. PLoS ONE 6: e23476. doi:10.1371/journal.pone.0023476

Landhäusser SM, Lieffers V (2012) Defolitaion increases risk of carbon starvation in root systems of mature aspen. Trees-Struct Funct 26:653-661

Larcher W (1995) Physiological plant ecology. Ecophysiology and stress physiology of functional groups. Springer, Berlin

Lemoine D, Cochard H, Granier A (2002) Within crown variation in hydraulic architecture in beech (Fagus sylvatica L.): evidence for a stomatal control of embolism. Ann For Sci 59: $19-27$

Levitt J (1980) Responses of plants to environmental stresses. Academic Press, New York

Li Y, Sperry JS, Taneda H, Bush SE, Hacke UG (2008) Evaluation of centrifugal methods for measuring xylem cavitation in conifers, diffuse- and ring-porous angiosperms. New Phytol 177:558-568

Lo Gullo MA, Nardini A, Salleo S, Tyree MT (1998) Changes in root hydraulic conductance of Olea oleaster seedlings following drought stress and irrigation. New Phytol 140:25-31

Lo Gullo MA, Salleo S (1991) Three different methods for measuring xylem cavitation and embolism: a comparison. Ann Bot London 67 (5):417-424

Lovelock C, Feller I, Ball M, Engelbrecht B, Ewe (2006) Differences in plant function in phosphorus- and nitrogen limited mangrove ecosystems. New Phytol 72:514-522

Luis VC, Llorca M, Chirino E, Hernández E, Vilagrosa A (2010) Differences in morphology, gas exchange and root hydraulic conductance before planting in Pinus canariensis seedlings growing under different fertilization and light regimes. Trees-Struct Funct 24:1143-1150

Luu DT, Maurel C (2005) Aquaporins in a challenging environment: molecular gears for adjusting plant water status. Plant Cell Environ 28:85-96 
Machado JL, Tyree MT (1994) Patterns of hydraulic architecture and water relations of two tropical canopy trees with contrasting leaf phonologies: Ochroma pyramidale and Pseudobombax septenatum Tree Physiol 14:219-240

Maherali H, Moura CF, Caldeira MC, Willson CJ, Jackson RB (2006) Functional coordination between leaf gas exchange and vulnerability to xylem cavitation in temperate forest trees. Plant Cell Environ 29:571-538

Maherali H, Pockman WT, Jackson RB (2004) Adaptative variation in the vulnerability of woody plants to xylem cavitation. Ecology 85:2184-2199

Markesteijn L, Poorter L, Bongers F, Paz H, Sack L (2011) Hydraulics and life history of tropical dry forest tree species: coordination of species' drought and shade tolerance. New Phytol 191:480-495

Martín JA, Solla A, Coimbra MA, Gil L (2005) Metabolic distinction of Ulmus minor xylem tissues after inoculation with Ophiostoma novo-ulmi. Phytochemistry 66:2458-2467

Martínez-Vilalta J, Cochard H, Mencuccini M, Sterck F, Herrero A, Korhonen JFJ, Llorens P, Nikinmaa E, Nolè A, Ripullone F, Sass-Klaassen U, Zweifel R (2009) Hydraulic adjustments of Scots pine across Europe. New Phytol 184:353-364

Martínez-Vilalta J, Prat E, Oliveras I, Piñol J (2002) Xylem hydraulic properties of roots and stems of nine Mediterranean woody species. Oecologia 133:19-29

Martre P, Morillon R, Barrieu F, North GB, Nobel PS, Chrispeels MJ (2002) Plasma membrane aquaporins play a significant role during recovery from water deficit. Plant Physiol 130:2101-2110

Maseda PH, Fernandez RJ (2006) Stay wet or else: three ways in which plants can adjust hydraulically to their environment. J Exp Bot 57:3963-3977

Maurel C, Verdoucq L, Luu DT, Santoni V (2008) Plant aquaporins: membrane channels with multiple integrated functions. Ann Rev Plant Biol. 59:595-624

Mayr S, Cochard H (2003) A new method for vulnerability analysis of small xylem areas reveals that compression wood of Norway spruce has lower hydraulic safety than opposite wood. Plant Cell Environ 26:1365-1371

Mayr S, Sperry JS (2010) Freeze-thaw-induced embolism in Pinus contorta: centrifuge experiments validate the 'thaw-expansion hypothesis' but conflict with ultrasonic emission data. New Phytol 185:1016-1024

Mayr S, Gruber A, Bauer H (2003) Repeated freeze-thaw cycles induce embolism in drought stressed conifers (Norway spruce, stone pine). Planta 217:436-41

Mayr S, Wieser G, Bauer H (2006) Xylem temperatures during winter in conifers at the alpine timberline. Agr Forest Meteorol 137:81-88

McCulloh K, Meinzer F, Sperry JS, Lachenbruch B, Voelker S, Woodruff JC (2011) Comparative hydraulic architecture of tropical tree species representing a range of successional stages and wood density. Oecologia 167:27-37

McDowell N, Pockman W, Allen D, Breshears D, Cobb N, Kolb T, Plaut J, Sperry J, West A, Williams D, Yepez EA (2008) Mechanisms of plant survival and mortality during drought: why do some plants survive while others succumb to drought? New Phytol 178:719-739

McElrone AJ, Jackson S, Habdas P (2008) Hydraulic disruption and passive migration by a bacterial pathogen in oak tree xylem. J Exp Bot 59:2649-2657

McElrone AJ, Pockman WT, Martínez-Vilalta J, Jackson RB (2004) Variation in xylem structure and function in stems and roots of trees to $20 \mathrm{~m}$ depth. New Phytol 163:507-517

Meinzer FC, Johnson DM, Lachenbruch B, McCulloh KA, Woodruff DR (2009) Xylem hydraulic safety margins in woody plants: coordination of stomatal control of xylem tension with hydraulic capacitance. Funct Ecol 23:922-930

Mencuccini, M, Comstock J (1997) Vulnerability to cavitation in populations of two desert species, Hymenoclea salsola and Ambrosia dumosa, from different climatic regions. J Exp Bot 48:1323-1334

Milburn JA. (1991) Cavitation and emboli, development and significance. In: Raghavendra AS (ed) Physiology of trees. Wiley, New York, pp 163-173

Milburn JA (1996) Sap ascent in vascular plants: challengers to the cohesion theory ignore the significance of immature xylem and the recycling of Münch water. Ann Bot 78:399-407 
Milburn JA, Johnson RPC (1966) The conduction of sap. II. Detection of vibrations produced by sap cavitation in Ricinus xylem. Planta 66:4-52

Miranda JD, Padilla FM, Martínez-Vilalta J, Pugnaire FI (2010) Woody species of a semiarid community are only moderately resistant to cavitation. Funct Plant Biol 37:828-839

Mitrakos K (1980) A theory for Mediterranean plant life. Acta Oecol-Oec Plant 1245-252

Morales F, Abadía A, Abadía J (2006) Photoinhibition and photoprotection under nutrient deficiencies, drought, and salinity. In: Demmig-Adams B, Adams III WW, Mattoo AK (eds) Photoprotection, photoinhibition, gene regulation and environment. Springer, Dordrecht, pp 65-85

Nardini A, Gascó A, Trifilo P, Lo Gullo MA, Salleo S (2007) Ion-mediated enhancement of xylem hydraulic conductivity is not always suppressed by the presence of $\mathrm{Ca}^{2+}$ in the sap. J Exp Bot 58:2609-2615

Nardini A, Grego F, Trifilò P, Salleo S (2010) Changes of xylem sap ionic content and stem hydraulics in response to irradiance in Laurus nobilis. Tree Physiol 30:628-635

Nardini A, Lo Gullo MA, Salleo S (2011) Refilling embolized xylem conduits: Is it a matter of phloem unloading?. Plant Sci 180: 604-611

Nardini A, Salleo S (2000) Limitation of stomatal conductance by hydraulic traits: sensing or preventing xylem cavitation? Trees-Struct Funct 15:14-24

Nardini A, Salleo S, Andri S (2005) Circadian regulation of leaf hydraulic conductance in sunflower (Helianthus annuиs L. cv. Margot). Plant Cell Environ 28:750-759

Nardini A, Tyree MT, Salleo S (2001) Xylem cavitation in the leaf of Prunus laurocerasus and its impact on leaf hydraulics. Plant Physiol 125:1700-1709

Naveh Z and Lieberman AS (1993) Landscape ecology theory and applications. ( $2^{\text {nd }}$ edn), Springer, New York

Netherer S, Schopf A (2010) Potential effects of climate change on insect herbivores general aspects and a specific example (Pine processionary moth, Thaumetopoea pityocampa). Forest Ecol Manag 259:831-838

Netting AG (2009) Limitations within "the limits to tree height". Brief communication. Am J Bot 96:542-544

Neufeld HS, Grantz DA, Meinzer FC, Goldstein G, Crisosto GM, Crisosto C (1992) Genotypic variability in vulnerability of leaf xylem to cavitation in water-stressed and well-irrigated sugarcane. Plant Physiol 100:1020-1028

Nobel PS (1999). Physicochemical and environmental plant physiology. Academic Press, San Diego, London

North GB, Martre P, Nobel PS (2004) Aquaporins account for variations in hydraulic conductance for metabolically active root regions of Agave deserti in wet, dry, and rewetted soil. Plant Cell Environ 27: 219-228

North GB, Nobel PS (1992) Drought-induced changes in hydraulic conductivity and structure in roots of Ferocactus acanthodes and Opuntia ficus-indica. New Phytologist 120:9-19

Ogaya R, Peñuelas J, Martínez-Vilalta J, Mangirón M (2003). Effect of drought on diameter increment of Quercus ilex, Phillyrea latifolia, and Arbutus unedo in a holm oak forest of NE Spain. Forest Ecol Manage 180:175-184

Oliveras I, Martínez-Vilalta J, Jimenez-Ortiz T, Lledó MJ, Escarré A, Piñol J (2003) Hydraulic properties of Pinus pinea and Tetraclinis articulata in a dune ecosystem of Eastern Spain. Plant Ecol 169:131-141

Pammenter NW, Vander Willigen C (1998) A mathematical and statistical analysis of the curves illustrating vulnerability of xylem to cavitation. Tree Physiol 18:589-593

Paula S, Ojeda F (2009) Belowground starch consumption after recurrent severe disturbance in three resprouter species of the genus Erica. Botany 87: 253-259

Peguero-Pina JJ, Alquézar-Alquézar JM, Mayr S, Cochard H, Gil-Pelegrín E (2011a) Embolism induced by winter drought may be critical for the survival of Pinus sylvestris L. near its southern distribution limit. Ann Sci 68:565-574

Peguero-Pina JJ, Morales F, Flexas J, Gil-Pelegrín E, Moya I (2008) Photochemistry, remotely sensed physiological reflectance index and de-epoxidation state of the xanthophyll cycle in Quercus coccifera under intense drought. Oecologia 156:1-11 
Peguero-Pina JJ, Sancho-Knapik D, Cochard H, Barredo G, Villarroya D, Gil-Pelegrín (2011b) Hydraulic traits are associated with the distribution range of two closely related Mediterranean firs, Abies alba Mill. and Abies pinsapo Boiss. Tree Physiol 31:1067-1075

Peguero-Pina JJ, Sancho-Knapik D, Morales F, Flexas J, Gil-Pelegrín E (2009) Differential photosynthetic performance and photoprotection mechanisms of three Mediterranean evergreen oaks under severe drought stress. Funct Plant Biol 36:453-462

Peman J, Voltas J, Gil-Pelegrin E (2006) Morphological and functional variability in the root system of Quercus ilex L. subject to confinement: consequences for afforestation. Ann For Sci 63:425-430

Pickard WF, Melcher PJ (2005) Perspectives on the biophysics of xylem transport. In: Holbrook NM and Zwieniecki MA (eds) Vascular transport in plants. Elsevier Academic Press, Burlington, San Diego, pp 4-18

Pittermann J, Choat B, Jansen S, Stuart SA, Lynn L, Dawson TE (2010) The Relationships between xylem safety and hydraulic efficiency in the Cupressaceae: The evolution of pit membrane form and function. Plant Physiol 153:1919-1931

Pittermann J, Sperry JS (2003) Tracheid diameter is the key trait determining the extent of freezing-induced embolism in conifers. Tree Physiol 23:907-914

Pittermann J, Sperry JS (2006) Analysis of freeze-thaw embolism in conifers: the interaction between cavitation pressure and tracheid size. Plant Physiol 140:374-382

Pittermann J, Sperry JS, Hacke U, Wheeler JK, Sikkema EH. 2006. Inter-tracheid pitting and the hydraulic efficiency of conifer wood: the role of tracheid allometry and cavitation protection. Am J Bot 93:1265-1273

Pockman WT, Sperry JS (1997) Freezing-induced xylem cavitation and the northern limit of Larrea tridentata. Oecologia 109:19-27

Pockman WT, Sperry JS (2000) Vulnerability to xylem cavitation and the distribution of Sonoran desert vegetation. Am J Bot 87:1287-1299

Pratt RB, Ewers FW, Lawson MC, Jacobsen AL, Brediger M, Davis SD (2005) Mechanisms for tolerating freeze-thaw stress of two evergreen chaparral species: Rhus ovata and Malosma laurine (Anacardiaceae). Am J Bot 92:1102-1113

Pratt RB, Jacobsen AL, Ewers FW, Davis SD (2007) Relationships among xylem transport, biomechanics and storage in stems and roots of nine Rhamnaceae species of the California chaparral. New Phytol 174:787-798

Pratt RB, North GB, Jacobsen AL, Ewers FW, Davis SD (2010) Xylem root and shoot hydraulics is linked to life history type in chaparral seedlings. Funct Ecol 24:70-81

Quero JL, Sterck FJ, Martínez-Vilalta J, Villar R (2011) Water-use strategies of six co-existing Mediterranean woody species during a summer drought. Oecologia 166:45-57

Raimondo F, Nardini A, Salleo S, Cacciola SA, LoGullo MA. 2010. A tracheomycosis as a tool for studying the impact of stem xylem dysfunction on leaf water status and gas exchange in Citrus aurantium $\mathrm{L}$. Trees 24:327-333

Richter H, Cruiziat P (2002) A brief history of the study of water movement in the xylem. Online document. Essay 4.1. Available via: http://5e.plantphys.net/article.php?ch=4\&id=98

Ryan MG (2011) Tree responses to drought. Tree Physiol 31:237-239

Sack L, Holbrook NM (2006). Leaf Hydraulics. Annu. Rev. Plant Biol 57:361-81

Sack L; Streeter CM, Holbrook NM (2004) Hydraulic analysis of water flow through leaves of sugar maple and red oak. Plant Physiol 134:1824-1833

Sangsing K, Kasemsap P, Thanisawanyangkura S, Sangkhasila K, Gohet E, Thaler P, Cochard H (2004) Xylem embolism and stomatal regulation in two rubber clones (Hevea brasiliensis Muell. Arg.). Trees-Struct Funct 18:109-114

Sala A. (2009) Lack of direct evidence for the carbon-starvation hypothesis to explain droughtinduced mortality in trees. PNAS 106:E68

Salleo S, Lo Gullo MA, De Paoli D, Zippo M (1996) Xylem recovery from cavitation induced embolism in young plants of Laurus nobilis, a possible mechanism. New Phytol 132:47-56

Salleo S, Lo Gullo MA, Raimondo F, Nardini A (2001) Vulnerability to cavitation of leaf minor veins: any impact on leaf gas exchange? Plant Cell Environ 24:851-859 
Salleo S, Nardini A, Pitt F, Lo Gullo MA (2000) Xylem cavitation and hydraulic control of stomatal conductance in Laurel (Laurus nobilis L.). Plant Cell Environ 23:71-79

Salleo S, Raimondo F, Trifilo P, Nardini A (2003) Axial-to-radial water permeability of leaf major veins: a possible determinant of the impact of vein embolism on leaf hydraulics? Plant Cell Environ 26:1749-1758

Salleo S, Trifilo P, Lo Gullo M (2006) Phloem as a possible major determinant of rapid cavitation reversal in stems of Laurus nobilis (laurel). Funct Plant Biol 33:1063-1074

Santiago LS, Goldstein G, Meinzer FC, Fisher JB, Machado K, Woodruff D, Jones T (2004) Leaf photosynthetic traits scale with hydraulic conductivity and wood density in Panamanian forest canopy trees. Oecologia 140:543-550

Shatil-Cohen A, Attia Z, Moshelion M (2011) Bundle-sheath cell regulation of xylem-mesophyll water transport via aquaporins under drought stress: a target of xylem-borne ABA? Plant $\mathrm{J}$ 67:72-80

Scholander PF, Hammel HT, Bradstreet ED, Hemmingsen EA (1965) Sap pressures in vascular plants. Science 148:339-346

Scoffoni C, Rawls M, McKown A, Cochard H, Sack L (2011) Decline of leaf hydraulic conductance with dehydration: relationship to leaf size and venation architecture. Plant Physiol 156:823-843

Sperry JS (1995) Limitations on stem water transport and their consequences. In: Gartner BL (ed) Plant stems: Physiology and functional morphology, Academy Press Limited, London, pp $105-124$

Sperry JS (2000) Hydraulic constraints on plant gas exchange. Agric For Meteorol 104:13-23

Sperry JS, Christman MA, Torrez-Ruiz JM, Taneda H, Smith DD (2011) Vulnerability curves by centrifugation: is there an open vessel artifact, and are " $\mathrm{r}$ " shaped curves necessarily invalid? Plant Cell Environ 35:601-610

Sperry JS, Donnelly JR, Tyree MT (1988) A method for measuring hydraulic conductivity and embolism in xylem. Plant Cell and Environ 83:414-417

Sperry JS, Nichols KL, Sullivan JEM, Eastlack SE (1994) Xylem embolism in ring-porous, diffuse-porous, and coniferous trees of Northern Utah and Interior Alaska. Ecology 75: $1736-1752$

Sperry JS, Saliendra NZ (1994) Intra- and inter-plant variation in xylem cavitation in Betula occidentalis. Plant Cell Environ 17:1233-1241

Sperry JS, Sullivan JEM (1992) Xylem embolism in response to freeze-thaw cycles and waterstress in ring-porous, diffuse-porous, and conifer species. Plant Physiol 100:605-613

Sperry JS, Tyree MT (1990) Water-stress-induced xylem embolism in three species of conifers. Plant Cell Environ 13:427-436

Spicer R, Gartner B (1998) Hydraulic properties of Douglas-fir (Pseudotsuga menziesii) branches and branch halves with reference to compression wood. Tree Physiol 18:777-784

Spicer R, Gartner B (2002) Compression wood has little impact on the water relations of Douglas-fir (Pseudotsuga menziesii) seedlings despite a large effect on shoot hydraulic properties. New Phytol 154:633-640

Steudle E (1995) Botany-trees under tension. Nature 378:663-664

Steudle E (2001) The cohesion-tension mechanism and the acquisition of water by plants root. Ann Rev Plant Physiol. Plant Mol Biol 52:847-875

Steudle E, Peterson CA (1998) How does water get through roots? J Exp Bot 49:775-788

Stiller V, Sperry JS (1999) Canny's compensating pressure theory fails a test. Amer J Bot 86:1082-1086

Stout DL, Sala A (2003) Xylem vulnerability to cavitation in Pseudotsuga menziesii and Pinus ponderosa from contrasting habitats. Tree Physiol 23:43-50

Thapa G, Dey M, Sahoo L, Panda SK (2011) An insight into the drought stress induced alterations in plants. Biol Plantarum 55:603-613

Tognetti R, Longobucco A, Raschi A (1998) Vulnerability of xylem to embolism in relation to plant hydraulic resistance in Quercus pubescens and Quercus ilex co-occurring in a Mediterranean coppice stand in central Italy. New Phytol 139:437-447 
Trifilo P, Nardini A, Lo Gullo MA, Salleo S (2003) Vein cavitation and stomatal behaviour of sunflower (Helianthus annuus) leaves under water limitation. Physiol Plant 119: 409-417

Trubat R, Cortina J, Vilagrosa A (2006) Plant morphology and root hydraulics are altered by nutrient deficiency in Pistacia lentiscus. Trees-Struct Funct 20:334-339

Tsuda M, Tyree MT (2000) Hydraulic conductance measured by the high pressure flow meter in crop plants. J Exp Bot 51:823-828

Tyree MT, Salleo S, Nardini A, Lo Gullo MA, Mosca R (1999) Refilling of embolized vessels in young stems of laurel. Do we need a new paradigm? Plant Physiol 120:11-21

Tyree MT (1997) The cohesion-tension theory of sap ascent: current controversies J Exp Bot 48:1753-1765

Tyree MT, Cochard H (1996) Summer and winter embolism in oaks: impact on water relations. Ann For Sci 53:173-180

Tyree MT, Cochard H, Cruiziat P, Sinclair B, Ameglio T (1993) Drought-induced leaf shedding in walnut: evidence for vulnerability segmentation. Plant Cell Environ 16:879-882

Tyree MT, Davis SD, Cochard H (1994) Biophysical perspectives of xylem evolution: is there a tradeoff of hydraulic efficiency for vulnerability to dysfunction? IAWA J 15:335-360

Tyree MT, Dixon MA, Thompson RG (1984) Ultrasonic acoustic emissions from the sapwood of Thuja occidentalis measured inside a pressure bomb. Plant Physiol 74:1046-1049

Tyree MT, Engelbrecht BMJ, Vargas G, Kursar TA (2003) Desiccation tolerance of five tropical seedlings in Panama. Relationship to a field assessment of drought performance. Plant Physiol 132:1439-1447

Tyree MT, Ewers FW (1991) The hydraulic architecture of trees and other woody plants. New Phytologist, 119:345-360

Tyree MT, Salleo S, Nardini A, Lo Gullo MA, Mosca R (1999) Refilling of embolized vessels in young stems of laurel. Do we need a new paradigm? Plant Physiol 120:11-21

Tyree MT, Sperry JS (1988) Do woody plants operate near the point of catastrophic xylem dysfunction caused by dynamic water stress? Plant Physiol 88:574-580

Tyree MT, Sperry JS (1989) Vulnerability of xylem cavitation and embolism. Ann Rev Plant Physol Mol Bio 40:19-38

Tyree MT, Yang S (1992) Hydraulic conductivity recovery versus water pressure in xylem of Acer saccharum. Plant Physiol 100:669-676

Tyree MT, Yang S, Cruiziat P, Sinclair B (1994) Novel methods of measuring hydraulic conductivity of tree root systems and interpretation using AMAIZED. A maize-root dynamic model for water and solute transport. Plant Physiol 104:189-199

Tyree MT, Zimmermann MH (2002) Xylem structure and the ascent of sap, $2^{\text {nd }}$ edition. SpringerVerlag, Berlin, Germany

Valladares F, Pearcy RW (1998) The functional ecology of shoot architecture in sun and shade plants of Heteromeles arbutifolia M. Roem., a Californian chaparral shrub. Oecologia 114:1-10

Valladares F, Vilagrosa A, Penuelas J, Ogaya R, Camarero JJ, Corchera L, Sisó S, Gil-Pelegrín E (2008) Estrés hídrico: ecofisiología y escalas de sequía. In: Valladares F (ed) Ecología del bosque mediterráneo en un mundo cambiante, 2nd edn. Organismo autónomo de parques nacionales. Ministerio de medio ambiente, Madrid, Spain, pp 165-192

Valliyodan B, Nguyen HT (2006) Understanding regulatory networks and engineering for enhanced drought tolerance in plants. Curr Opin Plant Biol 9:189-195

Van den Honert TH (1948) Water transport implants as a catenary process. Discussions of the Faraday Society 3:146-153

van Mantgem PJ, Stephenson NL, Byrne JC, Daniels LD, Franklin JF, Fulé PZ, Harmon ME, Larson AJ, Smith JM, Taylor AH et al. (2009) Widespread increase of tree mortality rates in the Western United States. Science 323:521-524

Vilagrosa A (2002). Estrategias de resistencia al déficit hídrico en Pistacia lentiscus L. y Quercus coccifera $\mathrm{L}$. PhD Thesis. Universidad de Alicante, Alicante (Spain)

Vilagrosa A, Bellot J, Vallejo VR, Gil-Pelegrín E (2003) Cavitation, stomatal conductance, and leaf dieback in seedlings of two co-occurring Mediterranean shrubs during an intense drought. J Exp Bot 54:2015-2024 
Vilagrosa A, Morales F, Abadía A, Bellot J, Cochard H, Gil-Pelegrín E (2010) Are symplast tolerance to intense drought conditions and xylem vulnerability to cavitation coordinated? An integrated analysis of photosynthetic, hydraulic and leaf level processes in two Mediterranean drought-resistant species. Environ Exp Bot 69:233-242

Vilagrosa A, Seva JP, Valcecantos A, Cortina J, Alloza JA, Serrasolses I, Diego V, Abril M, Ferran A, Bellot J, Vallejo VR (1997) Plantaciones para la restauración forestal en la comunidad Valenciana. In: La restauración de la cubierta vegetal en la comunidad Valenciana. V. R. Vallejo (Ed.). Pp: 435-598

Voicu M, Cooke JEK, Zwiazek JJ (2009) Aquaporin gene expression and apoplastic water flow in bur oak (Quercus macrocarpa) leaves in relation to the light response of leaf hydraulic conductance. J Exp Bot 60:4063-4075

Weatherley PE (1976) Introduction: water movement through plants. Phil Trans R Soc Lond B series 273:435-444

Wei C, Tyree MT, Steudle E (1999) direct measurement of xylem pressure in leaves of intact maize plants. A test of the cohesion-tension theory taking hydraulic architecture into consideration. Plant Physiol 121:1191-1205

Wheeler JK, Sperry JS, Hacke UG, Hoang N (2005) Inter-vessel pitting and cavitation in woody rosaceae and other vesselled plants: a basis for a safety vs. Efficiency trade-off in xylem transport. Plant Cell Environ 28:800-812

Wheeler TD, Stroock AD (2008) The transpiration of water at negative pressures in a synthetic tree. Nature, 455:208-212

Willats WG, McCartney L, Mackie W, Knox JP (2001) Pectin: cell biology and prospects for functional analysis. Plant Mol Biol 47:9-27

Williamson L, Ribrioux S, Fitter AH, Leyser MO 2001) Phosphate availability regulates root system architecture in Arabidopsis thaliana. Plant Physiol 126:875-882

Wortemann R, Herbette S, Barigah TS, Fumanal B, Alia R, Ducousso A, Gomory D, RoeckelDrevet P, Cochard H (2011) Genotypic variability and phenotypic plasticity of cavitation resistance in Fagus sylvatica L. across Europe. Tree Physiol 31:1-8

Yoshimura K (2011) Hydraulic function contributes to the variation in shoot morphology within the crown in Quercus crispula. Tree Physiol 31 774-781

Zeppel MJB, Henry D, Adams HD, Anderegg WRL (2011) Mechanistic causes of tree drought mortality: recent results, unresolved questions and future research needs. New Phytol 192:800-803

Zimmermann U, Meizer FC, Benkert R, Zhu JJ, Schneider H, Goldstein G, Kuchenbrod E, Haase A (1994) Xylem water transport: is the availabe evidence consistent with the cohesion theory? Plant Cell Environ 17:1169-1181

Zimmermann U, Schneider H, Wegner LH, Haase A. 2004. Water ascent in tall trees: does evolution of land plants rely on a highly metastable state? New Phytologist 162:575-615

Zufferey V, Cochard H, Ameglio T; Spring JL, Viret, O (2011). Diurnal cycles of embolism formation and repair in petioles of grapevine (Vitis vinifera cv. Chasselas). J Exp Bot 62:3885-3894

Zwieniecki MA, Holbrook NM (1998) Diurnal variation in xylem hydraulic conductivity in white ash (Fraxinus americana L.) red maple (Acer rubrum L.) and red spruce (Picea rubens Sarg.). Plant Cell Environ 21:1173-1180

Zwieniecki MA, Holbrook NM (2009) Confronting Maxwell's demon: biophysics of xylem embolism repair. Trends Plant Sci 14:530-534

Zwieniecki MA, Melcher PJ, Holbrook NM (2001) Hydrogel control of xylem hydraulic resistance in plants. Science 291:1059-1062 